3

24

\title{
Effects of processing parameters and blade patterns on continuous pharmaceutical powder mixing Juan G. Osorio ${ }^{1 *}$, Fernando J. Muzzio \\ Department of Chemical and Biochemical Engineering, Rutgers University
}

\section{Abstract}

The present study summarizes the experimental characterization of a new continuous powder mixer (GCG-70 by Glatt ${ }^{\circledR}$ ) using common pharmaceutical ingredients. The powder hold-up and residence time distribution were used to characterize the bulk behavior of the mixer as a function of impeller rotational speed, total throughput (mass flow rate) and blade configuration. The relative standard deviation (RSD), calculated from samples taken at the outlet of the blender, was used to characterize its mixing performance. The hold-up and the mean residence time decreased with increasing impeller rotational speed. The mean centered variance and the number of blade passes increased with increasing impeller rotational speed. The effect of the blade configuration on the mixing dynamics diminished as the rotation rate increased. The hold-up and mean residence time were sensitive enough to demonstrate the effects of blade configurations. The mixing performance, depending on the processing parameters, was found to be between $5 \%$ and $10 \%$ RSD for $5 \% \mathrm{w} / \mathrm{w}$ active pharmaceutical ingredient (API), and $<3 \%$ for $30 \% \mathrm{w} / \mathrm{w}$ API. These results showed improvements in the mixing performance when compared to studies of other continuous mixers using similar materials and analytical techniques for quantification.

Keywords: powders, continuous mixing, blade configuration, pharmaceuticals

*Corresponding Author: Department of Chemical Engineering, Massachusetts Institute of Technology, 77 Massachusetts Avenue, E19-532, Cambridge, MA, USA. Tel: 617-324-4324 Email address: josorio@ rutgers.edu 
2 Powder mixing is a critical manufacturing step in several industries, including

3 pharmaceuticals, cosmetics, chemicals, food and minerals. Especially in the pharmaceutical

4 industry, powder mixing is often carried out in batches. Therefore, batch powder mixing has

5 been characterized more extensively than continuous powder mixing. In recent years, a strong

6 initiative by the pharmaceutical industry and its regulatory agencies to understand, design and

7 control more robust manufacturing processes, leading to high quality finished products, has led

8 to growing interest in continuous processing [1].

9 Continuous processing offers several advantages over conventional batch processing $[2,3]$.

10 These advantages include the opportunity for more meaningful implementation of process

11 analytical technologies (PAT) and the use of modeling techniques for automated process control

12 to maintain the required steady state and make finished products with sustained quality [4]. With

13 continuous manufacturing, the same equipment used for process development can often be used

14 in manufacturing. Therefore, the need for process scale up is reduced or eliminated, accelerating

15 the introduction of new products to market. These advantages also include significant reductions

16 in equipment size and the ability for integration with other continuous processes (e.g. tableting,

17 capsule filling, roller compaction). Integration with an intrinsically continuous process would

18 yield higher process efficiency and minimize segregation of the mixed materials. Moreover,

19 because a continuous process can achieve a desired set point after a transient period of just a few

20 minutes, entire sets of designed experiments can often be explored in a matter of just a few days,

21 with great savings in materials, time and money. Overall, the advantages of continuous

22 processing can significantly reduce costs during development and manufacturing of 23 pharmaceuticals. 
2 and computationally [12-16] in the past few years. Such studies have described the mixing

3 behavior and performance of continuous mixers as a function of design parameters, processing

4 parameters and ingredient material properties. Design parameters include the impeller type and

5 configuration $[8,9,11]$, the outlet weir angle [8] and the mixer elevation angle [11]. Processing

6 parameters include the impeller rotational speed and the total and individual flow rates (mass

7 concentration) of the components [5,7-10]. However, only a few commercially available

8 continuous powder mixers have been discussed in the literature. Marikh et al. studied and

9 developed correlations for hold-up as a function of rotation rate for a continuous mixer (GCM-

10500 by Gericke with a length to diameter ratio (L:D) of 2.5) [10]. In a different study, using the

11 same continuous mixer, Marikh et al. investigated the effect of impeller types on hold-up and

12 mixing performance [9]. It was reported in both studies that mixing performance improved with

13 increasing rotation rate and then worsened at higher rotation rates due to the change in mixing

14 regimes (fluidization). Portillo et al. reported the characterization and comparison of two

15 continuous mixers (GEA Buck Systems with L:Ds of 4.9 and 6.2) with the same design but

16 different sizes $[6,11]$. In these studies, it was found that lower impeller rotation rates and a

17 greater upward mixer elevation angle yielded enhanced mixing performance. Vanarase and

18 Muzzio studied the effect of operating conditions and design parameters in a continuous powder

19 mixer (GCM-250 by Gericke with an L:D of 3.0) [8]. It was found that the total strain that the

20 powder experienced in the continuous mixer had a maximum at intermediate rotation rates also

21 yielding better mixing efficiency. In our previous work, we examined the mixing behavior of the

22 same continuous mixer (GC-250 by Gericke) using several pharmaceutical excipients differing 
1 in particle size and flow properties. It was found that although the material properties affected

2 mixing behavior, the predominant variable was still the impeller rotation rate [7].

3 Most of the continuous powder mixers characterized and reported in the literature were not

4 designed for pharmaceutical applications, but rather for food applications. In an effort to advance

5 the understanding of continuous powder mixing and processing as a whole, a new commercial

6 continuous powder mixer (Glatt GCG-70) - designed for pharmaceutical processing - was

7 considered in this study. The main objective of this study was to characterize the mixing

8 dynamics and performance of a Glatt GCG-70 using pharmaceutical powders. Contrary to liquid

9 mixers such as stirred tanks, where dozens of impeller geometries have been studied, very few

10 studies of the effects of impeller geometry on mixer performance have been reported for powder

11 mixers. Thus, in this study, the effects of blade configurations on mixing dynamics and

12 performance were studied as well.

13 2. Materials and Methods

14 2.1. Materials

15 Materials used in these studies are listed in Table 1. Silicified microcrystalline cellulose 16 (Prosolv HD 90) was used for the mixing dynamics and performance characterization, presented 17 in subsection 5.1. Microcrystalline cellulose (Avicel® PH 200) was used for the blade 18 configuration studies, presented in subsection 5.2. Magnesium stearate (MgSt) was used as the 19 instantaneous pulse material to characterize residence time distributions. Semi-fine 20 acetaminophen (APAP) was used to characterize the continuous mixing performance. 


\subsection{Continuous Mixing}

A new commercial continuous mixer (GCG-70, Glatt®), designed for pharmaceutical processing, was used in all the experiments presented in this article. The GCG-70 is $70 \mathrm{~cm}$ long and $8 \mathrm{~cm}$ in diameter (with an L:D of 8.75). The mixer and experimental set-up are shown in Figure 1. Two gravimetric feeders (Model AP300, Schenck Accurate) were used to feed the raw materials using the configurations described in Table 2. The selection of the screw type and nozzle size was based on previous experience, and it was dependent on the required flow rates and the cohesion of the individual components used, to minimize feeding variability.

\subsection{Sampling and Near-Infrared Analysis}

Stream sampling at the outlet of the continuous mixer was used. Samples were collected in 20-mL scintillation vials (Fisher Scientific) at different time intervals for the residence time distribution and blend uniformity measurements. Powder samples were analyzed in the vials using diffuse-reflectance near-infrared (NIR) spectroscopy. A Nicolet Antaris FT-NIR spectrometer (Thermo Electron) was used. The instrument measured the spectrum in the range of $4,000 \mathrm{~cm}^{-1}$ to $10,000 \mathrm{~cm}^{-1}$ wave numbers. Spectral data was collected using the software “Omnic." Calibration samples were prepared in $20-\mathrm{mL}$ scintillation vials in a vortex mixer (Fisher Scientific). The software "TQ Analyst" was used for calibration model development and quantification of the samples collected. Calibration samples were prepared by weighing $500 \mathrm{mg}$ of mixture into the scintillation vials using an Ohaus Explorer analytical balance with an accuracy of $\pm 0.01 \mathrm{mg}$. In all cases, the regression method used was partial least squares (PLS). The description, including the materials of interest and the concentration ranges, of the NIR calibration models used is summarized in Table 3. 
3. Mixing Characterization

\subsection{Hold-up}

The powder hold-up (Equation 1) is the amount of mass accumulation in the continuous mixer. The hold-up was measured by monitoring the mass of the powder being fed to the mixer and the mass of powder collected at the outlet of the mixer. The difference between the amount of powder being fed and the amount of powder collected at the outlet of the blender after steady state flow through the mixer was reached determines the hold-up.

Hold - up $=$ accumulation $=$ mass $_{\text {in }}-$ mass $_{\text {out }}$

\subsection{Residence Time Distribution}

The residence time distribution (RTD) and the calculated parameters from the RTD data describe the dispersion and the axial mixing behavior of continuous systems [17]. RTD in the continuous mixer was measured using the pulse experimental method. The main excipient (Avicel or Prosolv) was fed in the mixer until steady state mass flow (constant hold-up) was achieved. MgSt was used as the tracer and was introduced into the continuous mixer manually as an "instantaneous" pulse. The tracer amount (approximately 7-11 g depending on the flow rate and rotation rate) was chosen so that it could be detected using the analytical method (NIR spectroscopy) used in these studies. After the introduction of the tracer, samples were collected successively approximately every five seconds for two seconds from the outlet of the mixer in 20-mL scintillation glass vials, which were used to store and analyze the samples, for a total time of approximately 140 seconds. Samples were analyzed by NIR spectroscopy to determine the concentration of $\mathrm{MgSt}$ in them. Thus, for each experiment, the concentration of the tracer as a function of time $[c(t)]$ was determined. The RTD function $[E(t)]$, the mean residence time (MRT, $\tau)$ and the mean centered variance $\left(\mathrm{MCV}, \sigma_{\tau}{ }^{2}\right.$ ) were calculated. Mathematical expressions for the 
1 RTD, the MRT and the MCV are described in equations 2, 3 and 4, respectively. The RTD

2 describes the probability distribution of the time that a particle would spend inside the

3 continuous mixer. The MRT, as its name implies, determines the average time that a tracer

4 particle spends inside the continuous mixer. The MCV describes the width of the RTD curve and

5 it is inversely related to the number of ideal stirred tanks in series that would describe the same

6 RTD.

$7 \quad E(t)=\frac{c(t)}{\int_{0}^{\infty} c(t) d t}$

8

$9 \tau=\int_{0}^{\infty} t E(t) d t$

10

$11 \quad \sigma_{\tau}^{2}=\frac{\int_{0}^{\infty}(t-\tau)^{2} E(t) d t}{\tau^{2}}$

12

13 3.3. Number of blade passes (Strain)

14 The number of blade passes is an indirect measurement of the amount of strain, correlated to

15 the energy input caused by the impeller, that the powder experiences inside a continuous mixer

$16[6,8,11]$. The number of blade passes $\left(N_{p}\right)$ is proportional to the product of the rotation rate $(\omega)$

17 and the mean residence time $(\tau)$, shown in Equation 5.

$18 \quad N_{P}=\omega \cdot \tau$

\subsection{Blend Uniformity}

20 The blend uniformity was determined using the relative standard deviation (RSD). Samples

21 were collected successively approximately every 10 seconds for approximately three seconds

22 from the outlet stream using 20-mL scintillation vials. The RSD, also known as the coefficient of 
1 variability, is the most common mixing index used, and was calculated from the measured

2 concentration of 20 samples for each experimental run. The acetaminophen concentration from

3 each sample was quantified by using the NIR spectroscopy. The RSD is the ratio of the sample

4 standard deviation $(s)$ and the mean concentration $(\bar{C})$ of the material of interest (Equation 6).

$5 \quad R S D=\frac{s}{\bar{C}}$, for $s=\sqrt{\frac{\sum_{1}^{N}\left(C_{i}-\bar{C}\right)^{2}}{N-1}}$

6 where $C_{i}$ is the measured concentration of sample $i$ and $N$ is the total number of samples.

8 4. Experimental Conditions

9 4.1. Mixing characterization

10 The first part of this paper presents the characterization of the mixing dynamics and 11 performance of the continuous mixer under investigation. A full factorial experimental design 12 was performed using three flow rates $(15,30$ and $45 \mathrm{~kg} / \mathrm{hr})$ and three rotation rates $(112,286$ and 13495 RPM). The mixing dynamics and performance were characterized by measuring hold-up, 14 residence time distribution and blend uniformity. Prosolv HD90 was used as the main excipient, $15 \mathrm{MgSt}$ as the instantaneous pulse material for the RTD measurements, and semi-fine APAP was 16 used as the active pharmaceutical ingredient (API), with a target concentration of 5\% w/w, for 17 the mixing performance characterization.

\subsection{Blade Configurations}

In the second part of this paper, the effect of blade configuration, varying in blade type 20 (Figure 2 and Table 4) and orientation with respect to the horizontal axis, on the mixing 21 dynamics and performance of the continuous mixer is summarized. All the blades, 24 in total, in 
1 the impeller were at a $45^{\circ}$ angle. The blade configurations are described as follows: (1) all-

2 forward - all the blades convey the flow forward; (2) $1 / 2$ all forward $+1 / 2$ alternate - the first

3 half of the blades convey the flow forward and the second half of the blades alternates, one blade

4 conveying the flow forward and one blade conveying the flow backwards; and (3) 1/3 all-

5 forward $+1 / 3$ alternate $+1 / 3$ all forward - the blades in the first third of the impeller convey the

6 flow forward, the blades in the second third of the impeller alternates, one blade conveying the

7 flow forward and one blade conveying the flow backwards, and the blades in the last third of the

8 impeller convey the flow forward. For the blade configurations composed of more than one

9 blade type, for example "Angled+Small" (Figure 2B), the angled blade was the first blade

10 (closest to the inlet) in the impeller followed by a small blade followed an angled blade followed

11 by a small blade and so on and so forth. For sake of brevity and to characterize the main effects

12 of blade configurations, extreme operating conditions were investigated. Two flow rates (15 and

$1345 \mathrm{~kg} / \mathrm{hr}$ ) and two rotational speeds (112 and $495 \mathrm{RPM}$ ) for the five blade configurations

14 described in Table 4 were used. The effect of blade configuration on hold-up, residence time and

15 blend uniformity (RSD) was characterized. Avicel PH 200 was used as the main excipient, MgSt

16 as the instantaneous pulse material for the RTD measurements, and semi-fine acetaminophen

17 was used as the API (with a target concentrations of $5 \%$ and $30 \% \mathrm{w} / \mathrm{w}$ ) for the mixing 18 performance characterization.

20 5. Results and Discussion

21 5.1. Effect of process parameters on mixing dynamics and blend uniformity

22 In this subsection, the effects of process parameters (impeller rotation rate and flow rate) on 23 the hold-up, RTD, MRT, MCV, and $N_{p}$ are presented. The blend uniformity (RSD) of the 
1 continuous mixer as a function of process parameters is presented as well. Experimental results

2 in this section were performed using blade configuration \#2 (Angled+Flat, all-forward).

$3 \quad$ 5.1.1. Effect of process parameters on hold-up

$4 \quad$ The hold-up significantly decreased with increasing rotation rate for all feed rates used as

5 shown in Figure 3. This change was statistically significant with $p$-value of 0.001 . This trend was

6 observed in other continuous mixers and was expected [8-10]. The rotation rate had the greatest

7 effect on hold-up with an $F$-value of 50.11. In addition, the hold-up significantly increased ( $p$ -

8 value $=0.023)$ with increasing flow rate. This was particularly true at lower rotation rates (112

9 RPM). At higher rotation rates, the hold-up was considerably lower for $15 \mathrm{~kg} / \mathrm{hr}$, while for 30

$10 \mathrm{~kg} / \mathrm{hr}$ and $45 \mathrm{~kg} / \mathrm{hr}$, the hold-up was very similar. A summary of the analysis of variance

11 (ANOVA) for all responses, including hold-up, is shown in Table 5.

12

13

\section{1 .2 .}

Effect of process parameters on residence time distribution

The residence time distribution (RTD) for flow rate at $30 \mathrm{~kg} / \mathrm{hr}$ is shown in Figure 4. This results show a longer delay in the detection of the tracer for 112RPM followed by 286 RPM and 495 RPM. To better understand the meaning of and to summarize the RTD results, the mean residence time (MRT, $\tau)$ and the mean centered variance $\left(\mathrm{MCV}, \sigma_{\tau}^{2}\right)$ are described as a function of rotation rate and flow rate in Figure 5. The MRT significantly decreased $(p$-value $<0.05)$ with increasing rotation rate (Figure 5A). This means that the powder inside the continuous mixer spends more time at lower rotation rate. On the other hand, the MCV significantly increased ( $p$ value $<0.05$ ) with increasing rotational speed (Figure 5B), leading to a wider RTD at higher rotational speeds. The inverse of the mean centered variance yields the equivalent number of ideal stirred tanks in series that would provide a comparable RTD. The number of ideal stirred tanks in series indicates the degree of dispersion of the instantaneous pulse used. Fewer stirred 
1 tanks in series (higher MCV) represent faster dispersion, and thus quicker axial mixing. For

2 example at $15 \mathrm{~kg} / \mathrm{hr}$, the MRT at $112 \mathrm{RPM}$ was 114 seconds while at $495 \mathrm{RPM}$ it was 77

3 seconds. For these same values, the MCV increased from 0.204 to 0.414 which represent a

4 decrease from 5 to $\sim 2.5$ stirred tanks in series. Although higher rotation rate gives rise to better

5 axial mixing, it also decreases the amount of time available for mixing. The same trends were

6 previously observed in a different continuous mixer (GCM-250 by Gericke) studied by Vanarase

7 and Muzzio [8]. This confirms that this trade-off effect between the MRT and the MCV can be

8 expected for cylindrical continuous mixers.

The RTD measurements for all three flow rates at 286 RPM is shown in Figure 6. The 10 sharpest and narrower RTD was given by $45 \mathrm{~kg} / \mathrm{hr}$ followed by $30 \mathrm{~kg} / \mathrm{hr}$ and $15 \mathrm{~kg} / \mathrm{hr}$. The MRT

11 significantly decreased ( $p$-value $<0)$ with increasing flow rate (Figure 5A). This means that the

12 amount of time that the powder spends inside the continuous mixer decreases with increasing

13 flow rate. In another study, Vanarase and Muzzio obtained the same effect, in which the MRT 14 decreased with increasing flow rate for 30 and $45 \mathrm{~kg} / \mathrm{hr}$ [8]. In our study, the results show that 15 the MRT values are more similar for 30 and $45 \mathrm{~kg} / \mathrm{hr}$ than those obtained at $15 \mathrm{~kg} / \mathrm{hr}$. This is 16 important to point out since as more powder is flowing through the blender, it is also spending 17 less time and might not achieve efficient mixing. Therefore, at higher flow rates, it is recommended to operate at lower rotation rates. The effect of flow rate $(F$-value $=226.71)$ on the

19 MRT was larger than the effect of rotation rate $(F$-value $=55.49)$. This means that flow rate had 20 a greater influence on the MRT in the continuous mixer under investigation. Finally, the MCV 21 did not display a clear trend due to variations in flow rate (Figure 5B). In addition, the flow rate 22 did not generate a significant change on the MCV $(p$-value $=0.357)$.

$23 \quad$ 5.1.3. Effect of process parameters on number of blade passes 
A useful measurement obtained from the MRT is the number of blade passes $\left(N_{p}\right)$, which can

2 be used as an estimate of the mean strain that the powder experiences inside the continuous

3 mixer. In this case, the number of blade passes substantially increased $(p$-value $<0)$ with

4 increasing rotation rate (Figure 7). In previous work by Portillo et al., the number of blade passes

5 also increased with increasing rotation rate in a mixer of similar geometry $[6,11]$. In the work by

6 Vanarase and Muzzio, which explored a wider range of rotation rates, the number of blade

7 passes had a maximum at intermediate rotation rates [8]. In contrast, the mixer studied in this

8 study does not display a maximum number of blade passes even though the rotational speeds are

9 higher than in the cited works. This difference in trends can be attributed to the difference in 10 geometrical dimensions of the continuous blenders, i.e. the length to diameter ratio (L:D) and the 11 number of blades used in the mixer. The continuous mixers used by Portillo had L:Ds of 4.9 and 126.2 while the continuous mixer used by Vanarase had an L:D of 3.0. In this case, the continuous 13 mixer used had an L:D of 8.75.

The number of blade passes $\left(N_{p}\right)$ significantly decreased $(p$-value $<0)$ with increasing flow 15 rate (Figure 7). The rate at which the number of blade passes decreased was lower at lower 16 rotation rates. The largest difference in the number of blade passes was achieved at the highest 17 rotation rate, $495 \mathrm{RPM}$ (between $15 \mathrm{~kg} / \mathrm{hr}$ and $30 \mathrm{~kg} / \mathrm{hr}$ ). The interaction between the flow rate 18 and the rotation rate on the number of blade passes was statistically significant $(p$-value $<0)$. 19 Although rotation rate had a larger quantified contribution to the changes in the number of blade 20 passes, these are similar with $F$-values of 390.72 and 302.85 for rotation rate and flow rate, 21 respectively.

5.1.4. $\quad$ Effect of process parameters on blend uniformity 
The blend uniformity of the continuous mixer, as measured by the relative standard deviation

2 (RSD), is shown in Figure 8. A target concentration of 5\% w/w APAP was used in this case. No

3 trends between the RSD and the rotation rate were found. In fact, the differences due to rotation

4 rate were not statistically significant ( $p$-value $=0.273$ ). For 15 and $30 \mathrm{~kg} / \mathrm{hr}$, a minimum RSD

5 was obtained at the intermediate rotation rate (286 RPM) but this was not true for $45 \mathrm{~kg} / \mathrm{hr}$. In

6 addition, there was no clear trend in the RSD due to flow rate, although the differences due to

7 flow rate were still statistically significant $(p$-value $=0.082)$.

8 The large error bars indicate that the true RSD can be anywhere between the specified 9 ranges. The errors bars were calculated using the results from Gao et al., who studied the 10 determination of RSD confidence intervals using convolution [18]. The large error bars are 11 mainly a product of the small number of samples (20) used. This small number of samples is 12 typically used in the pharmaceutical industry when characterizing the blend uniformity and final 13 product (e.g. tablets) content uniformity. The RSD results obtained were in the range of $6 \%$ to $1410 \%$. Such RSD results were comparable to the results obtained by Portillo [6,11] and lower than 15 those obtained by Vanarase and Muzzio [8] in the characterization of different continuous mixers 16 using similar materials and the same analytical method (NIR spectroscopy). In addition, the 17 small amount of sample used and the analytical error occurring as a result of using NIR might 18 underrepresent the blend uniformity obtained in this and other studies. The root mean square error of prediction (RMSEP) for the NIR calibration model was 0.297 in this case, which would 20 only allow for the lowest measurable RSD to be $\sim 5.9 \%(100 \% * 0.297 \div 5)$.

21 

and two impeller rotation rates (112 and 495 RPM) using Avicel PH 200. The effect of blade configuration on hold-up is shown in Figure 9. For $15 \mathrm{~kg} / \mathrm{hr}$ at impeller speed of $112 \mathrm{RPM}$

4 (Figure 9A), the hold-up was the lowest for the all-forward with angled blades configuration 5 (\#1). The hold-up was slightly larger for the all-forward with angled and flat blades 6 configuration (\#2), followed by the $1 / 3$ all-forward $+1 / 3$ alternate $+1 / 3$ all-forward blade 7 configuration with the angled and flat blades (\#3). On the other hand, the hold-up was largest for 8 the blade configurations with the angled and small blades, having the second largest value for the 9 all-forward blade configuration (\#4) and the highest for the $1 / 2$ all forward $+1 / 2$ alternate blade configuration (\#5). These changes in hold-up were statistically significant $(p$-value $=0.040)$. A

11 summary of the ANOVA for the effect of blade configuration an all responses, including hold12 up, is shown in Table 6.

The observed trend can be explained by the size variation (i.e. total area) of the blade types 14 as well as the blade configuration and orientation of the blades (Figure 2). Blade configuration 15 \#1 was composed of the largest blade (angled) only, with all of them directing the powder flow 16 forward. This configuration conveyed more powder when compared to the other blade 17 configurations. Blade configuration \#2 was composed of the angled and flat blades, in an 18 alternating sequence, with all of them directing the flow forward. The flat blades are smaller in 19 size than the angled blades. Therefore the hold-up increased due to a reduction in the total blade area available for powder transport when using this blade configuration. Blade configuration \#3

21 was composed of the angled and flat blades, with a 1/3 blade configuration that alternated the 22 orientation of the blades by directing the flow forward and then backwards. This alternating 23 configuration, in the second third of the impeller, was expected to increase the recirculation of 
1 the powder and, thus, the hold-up. For blade configurations \#4 and \#5, the use of the small

2 blades in the impeller substantially decreased the amount of powder that could be transported

3 through convection by the impeller. The alternating blade configuration in configuration \#5 also

4 created substantial recirculation in the second half of the impeller yielding the highest hold-up.

5 Two flow patterns can be easily identified when studying the effect of blade configuration on

6 the hold-up [13]. These can be described as the "recirculation" (increasing dispersion) pattern

7 and the "forward convection" pattern. The recirculation pattern determines the amount of powder

8 that is held back in the blender by blades that direct the flow backwards. The convection pattern

9 determines the amount of powder that is held in the blender as it is "pumped" forward by the

10 blades. Smaller blades might also create larger stagnant regions in which the powder might not

11 be flowing (conveyed) at all. Therefore blade configuration \#5 was expected to yield the highest

12 hold-up due to an increase in the recirculation created by the $1 / 2$ alternating blade configuration

13 as well as the reduction in the effective blade area available for powder convection.

14 The same trend in hold-up was obtained for $15 \mathrm{~kg} / \mathrm{hr}$ at $495 \mathrm{RPM}$ (Figure 9B). In this case, 15 the hold-up decreased substantially with increasing rotation rate (expected) for all blade 16 configurations except for blade configuration \#5. In this case, the rotation rate had a minor effect

17 on the hold-up. This further suggests the possibility of larger stagnant regions created by a less 18 effective convective mechanism for this blade configuration even at higher rotational speeds. For $45 \mathrm{~kg} / \mathrm{hr}$ at $112 \mathrm{RPM}$ (Figure 9C) and $495 \mathrm{RPM}$ (Figure 9D), the effect of the blade 20 configuration was the same but the differences in hold-up values between blade configurations 21 were substantially smaller. At $45 \mathrm{~kg} / \mathrm{hr}$, a strong interaction between the flow rate and the 22 impeller rotational speed was observed causing the hold-up for all blade configurations to be 23 similar to each other. This can be an indication that powder convection is stronger due to the 
1 bulk flow while the effect of blade configuration is less significant at higher flow rates. A

2 summary of the ANOVA (Table 6) shows that the flow rate and rotation rates have larger effects

3 on the hold-up than the blade configurations with F-values of 18.63, 57.49, and 7.33,

4 respectively.

5

$6 \quad$ 5.2.2. Effect of blade configuration on mean residence time

7 The effect of blade configuration on the MRT $(\tau)$ for all experiments in this section are

8 plotted in Figure 10. The MRT showed a clear trend, similar to the hold-up results as expected.

9 In general, the MRT for blade configuration \#5 was higher for all experimental conditions when

10 compared to all the other blade configurations, as expected, followed by configurations \#4

11 through \#1, in that order. These differences in MRT caused by the blade configuration were

12 statically significant ( $p$-value $=0.022$ ). For $45 \mathrm{~kg} / \mathrm{hr}$, the MRT was lower and almost identical for

13 all blade configurations, especially at 495 RPM. The recirculation and the convective

14 mechanisms previously described also explain the effect of blade configuration on the MRT. As

15 the rotation rate increases, the MRT results for the blade configurations become almost identical.

16 At higher rotation rates, the rotational forces in the shaft overcome the influence of the blade

17 configuration. This means that the convective mechanism governs mixing and the recirculation

18 mechanism created by the alternating blade configurations no longer has a significant effect on

19 the RTD. In previous work by Vanarase and Muzzio [8], comparison of two blade configurations

20 showed opposite results. Their findings described that the MRT was similar at lower rotation

21 rates and became substantially different at higher rotation rates for blade configurations with

22 forward and alternate configurations. In their case, the MRT was also higher for an alternating

23 blade configuration, which created more recirculation of the powder inside the continuous mixer. 
1 Nevertheless, the blade configurations studied as well as the L:D of the mixer were very

2 different. The summary of the ANOVA for MRT for the effect of blade configuration is shown

3 in Table 6.

$4 \quad$ 5.2.3. Effect of blade configuration on blend uniformity

5 The effect of blade configuration on the blend uniformity in the continuous mixer was also

6 examined (Figure 11). In this case, a blend with $30 \%$ semi-fine acetaminophen in a common

7 excipient (Avicel PH200) was used. The blend uniformity (indicated by the RSD) was very

8 similar for all blade configurations for the flow rates and impeller rotational speeds used.

9 Therefore only the results for $15 \mathrm{~kg} / \mathrm{hr}$ and $112 \mathrm{RPM}$ are included. All RSD results were below

$103 \%$ indicating good mixing. These differences and lack of trend could potentially be caused by

11 statistical scatter of the data represented by the error bars. These RSD results are dominated by

12 the NIR error, the root mean square error of prediction (RMSEP), with a value of 0.361 .

13 Therefore the minimum RSD that could be obtained using this NIR calibration model would be

$141.2 \%(100 \% * 0.36 \div 30)$. Nevertheless, it can be concluded that for $30 \%$ APAP, all the

15 experimental parameters generated desired mixing levels of much less than $6 \%$ RSD. In another

16 study, Marikh et al. investigated the effect of two agitators in continuous mixing of APIs, similar

17 in particle size and nominal concentration $(23 \% \mathrm{w} / \mathrm{w})$ [9]. The RSD values obtained in their

18 investigations were higher than those from the current study. Although it is hard to compare

19 different continuous mixers with different geometries, impellers, and materials, it can be said that

20 the continuous mixer characterized in this study, specifically designed for pharmaceutical

21 formulations, is efficient when mixing high concentration $(\sim 30 \% \mathrm{w} / \mathrm{w})$ of cohesive APIs.

22 To elucidate the effect of blade configuration on the blend uniformity for a low concentration

23 of API $(5 \% \mathrm{w} / \mathrm{w})$, blade configuration \#3 was tested for more flow rates and rotational speeds 
1 and compared to blade configuration \#2 (as described in subsection 5.1) using Prosolv HD90 as

2 the bulk excipient. Even at low concentration of API, the RSDs were not different for the blade

3 configurations tested. In fact, the effect of blade configuration was not statistically significant ( $p$ -

4 value $=0.922$ ). Graphs and ANOVA for these results were omitted for sake of brevity. Overall,

5 the determination of which blade configuration is "better" or "worse" has to be determined from

6 the hold-up and mean residence time. Therefore the effect of hold-up and mean residence time

7 on other final blend properties such as degree of lubrication and flow properties plays an

8 important role. The mixer characterized in this study yielded blends with consistent blend

9 uniformity regardless of the process parameters and blade configurations used.

11 6. Conclusions

12 A new continuous powder mixer designed specifically for pharmaceutical blending was 13 studied in detail. The effect of process parameters (flow rate and rotational speed) on hold-up, 14 residence time distribution and blend uniformity (RSD) was investigated. Overall, the hold-up 15 and the mean residence time decreased with increasing impeller rotational speed. The mean 16 centered variance and the number of blade passes increased with increasing impeller rotational 17 speed. The hold-up increased with increasing flow rate. The mean residence time and the number 18 of blade passes decreased with increasing flow rate.

The effect of the blade configuration on the mixing dynamics was also studied. This effect 20 diminished as the rotation rate increased. The hold-up and the mean residence time were 21 sensitive enough to demonstrate the effects of the blade configuration on the mixing behavior in 22 the continuous blender. The convective and the recirculation mechanisms were explained by the 23 blade configuration studies. Overall, mixing performance (blend uniformity) was found to be 
1 robust with respect to processing parameters and blade configurations. The RSD was found to be

2 less than $3 \%$ for $30 \%$ w/w API (acetaminophen) concentration, and between 5\% and 10\% RSD

3 for 5\% w/w API concentration. These results showed improvements in the mixing performance

4 obtained from studies of other continuous blenders using similar materials and the same

5 analytical method.

6

7 Acknowledgements

8 This work was possible through funding from the National Science Foundation (NSF)

9 Engineering Research Center for Structured Organic Particulate Systems (C-SOPS) and Janssen 10 Pharmaceuticals.

\section{References}

12 [1] L. Yu, Pharmaceutical Quality by Design: Product and Process Development,

14 [2] J.C. Williams, Continuous mixing of solids. A review, Powder Technol. 15 (1976) 237243.

[3] J.G. Osorio, A.U. Vanarase, R.J. Romañach, F.J. Muzzio, Continuous Powder Mixing, in:

17 P.J. Cullen, R.J. Romañach, N. Abatzoglou, C.D. Rielly (Eds.), Pharmaceutical Blending and Mixing, John Wiley \& Sons, Ltd., 2015: pp. 101-127.

19 [4] H. Wu, M. Tawakkul, M. White, M.A. Khan, Quality-by-Design (QbD): An integrated multivariate approach for the component quantification in powder blends, Int. J. Pharm. 372 (2009) 39-48.

22 [5] H. Berthiaux, K. Marikh, C. Gatumel, Continuous mixing of powder mixtures with 
pharmaceutical process constraints, Chem. Eng. Process. Process Intensif. 47 (2008) $2315-2322$.

[6] P.M. Portillo, M.G. Ierapetritou, F.J. Muzzio, Effects of rotation rate, mixing angle, and cohesion in two continuous powder mixers-A statistical approach, Powder Technol. 194 (2009) 217-227.

[7] A.U. Vanarase, J.G. Osorio, F.J. Muzzio, Effects of powder flow properties and shear environment on the performance of continuous mixing of pharmaceutical powders, Powder Technol. 246 (2013) 63-72.

[8] A.U. Vanarase, F.J. Muzzio, Effect of operating conditions and design parameters in a continuous powder mixer, Powder Technol. 208 (2011) 26-36.

[9] K. Marikh, H. Berthiaux, C. Gatumel, V. Mizonov, E. Barantseva, Influence of stirrer type on mixture homogeneity in continuous powder mixing: A model case and a pharmaceutical case, Chem. Eng. Res. Des. 86 (2008) 1027-1037.

[10] K. Marikh, H. Berthiaux, V. Mizonov, E. Barantseva, Experimental study of the stirring conditions taking place in a pilot plant continuous mixer of particulate solids, Powder Technol. 157 (2005) 138-143.

[11] P.M. Portillo, M.G. Ierapetritou, F.J. Muzzio, Characterization of continuous convective powder mixing processes, Powder Technol. 182 (2008) 368-378.

[12] K. Marikh, H. Berthiaux, V. Mizonov, E. Barantseva, D. Ponomarev, Flow Analysis and Markov Chain Modelling to Quantify the Agitation Effect in a Continuous Powder Mixer, Chem. Eng. Res. Des. 84 (2006) 1059-1074.

[13] Y. Gao, M. Ierapetritou, F. Muzzio, Investigation on the effect of blade patterns on continuous solid mixing performance, Can. J. Chem. Eng. 89 (2011) 969-984. 
1 [14] A. Sarkar, C.R. Wassgren, Simulation of a continuous granular mixer: Effect of operating conditions on flow and mixing, Chem. Eng. Sci. 64 (2009) 2672-2682.

3 [15] A. Sarkar, C.R. Wassgren, Comparison of flow microdynamics for a continuous granular $4 \quad$ mixer with predictions from periodic slice DEM simulations, Powder Technol. 221 (2012) 325-336.

6 [16] H. Berthiaux, K. Marikh, V. Mizinov, D. Ponomarev, E. Barantzeva, Modeling Continuous Powder Mixing by Means of the Theory of Markov Chains, Part. Sci. Technol. 22 (2004) 379-389.

9 [17] E.B. Nauman, Residence Time Theory, Ind. Eng. Chem. Res. 47 (2008) 3752-3766.

10 [18] Y. Gao, M. Ierapetritou, F. Muzzio, Determination of the Confidence Interval of the Relative Standard Deviation Using Convolution, J. Pharm. Innov. 8 (2013) 72-82. 
Figure 1 - Equipment: (A) continuous mixer and (B) feeder-mixer setup

Figure 2 - (A) Blades and (B) blade configuration \#4

Figure 3 - Hold-up as a function of rotation rate and flow rate. Blade configuration \#2: Angled+Flat, All-forward.

Figure 4 - Residence time distribution $(E(t))$ as a function of rotation rate for flow rate of 30 $\mathrm{kg} / \mathrm{hr}$. Blade configuration \#2: Angled+Flat, all forward.

Figure 5 - Effect of rotation rate and flow rate on (A) mean residence time $(\tau)$ and $(\mathrm{B})$ mean centered variance $\left(\sigma_{\tau}^{2}\right)$. Blade configuration \#2: Angled+Flat, all forward.

Figure 6 - Effect of flow rate on residence time distribution $(E(t))$ at 286 RPM. Blade configuration \#2: Angled+Flat, all forward.

Figure 7 - Effect of rotation rate and flow rate on number of blade passes $\left(N_{p}\right)$. Blade configuration \#2: Angled+Flat, all forward.

Figure 8 - Effect of rotation rate and flow rate on blend uniformity (RSD). Target concentration: $5 \%$ w/w acetaminophen. Blade configuration \#2: Angled+Flat, all forward.

Figure 9 - Effect of blade configuration (x-axis) on hold-up at (A) $15 \mathrm{~kg} / \mathrm{hr}$ and $112 \mathrm{RPM}$, (B) $15 \mathrm{~kg} / \mathrm{hr}$ and $495 \mathrm{RPM}$, (C) $45 \mathrm{~kg} / \mathrm{hr}$ and $112 \mathrm{RPM}$, and (D) $45 \mathrm{~kg} / \mathrm{hr}$ and $495 \mathrm{RPM}$.

Figure 10 - Effect of blade configuration on mean residence time $(\tau)$ at (A) $15 \mathrm{~kg} / \mathrm{hr}$ and 112 RPM, (B) $15 \mathrm{~kg} / \mathrm{hr}$ and $495 \mathrm{RPM}$, (C) $45 \mathrm{~kg} / \mathrm{hr}$ and $112 \mathrm{RPM}$, and (D) $45 \mathrm{~kg} / \mathrm{hr}$ and $495 \mathrm{RPM}$.

Figure 11 - Effect of blade configuration on blend uniformity (RSD) at $15 \mathrm{~kg} / \mathrm{hr}$ and $112 \mathrm{RPM}$. Semi-fine acetaminophen target concentration: $30 \% \mathrm{w} / \mathrm{w}$. 


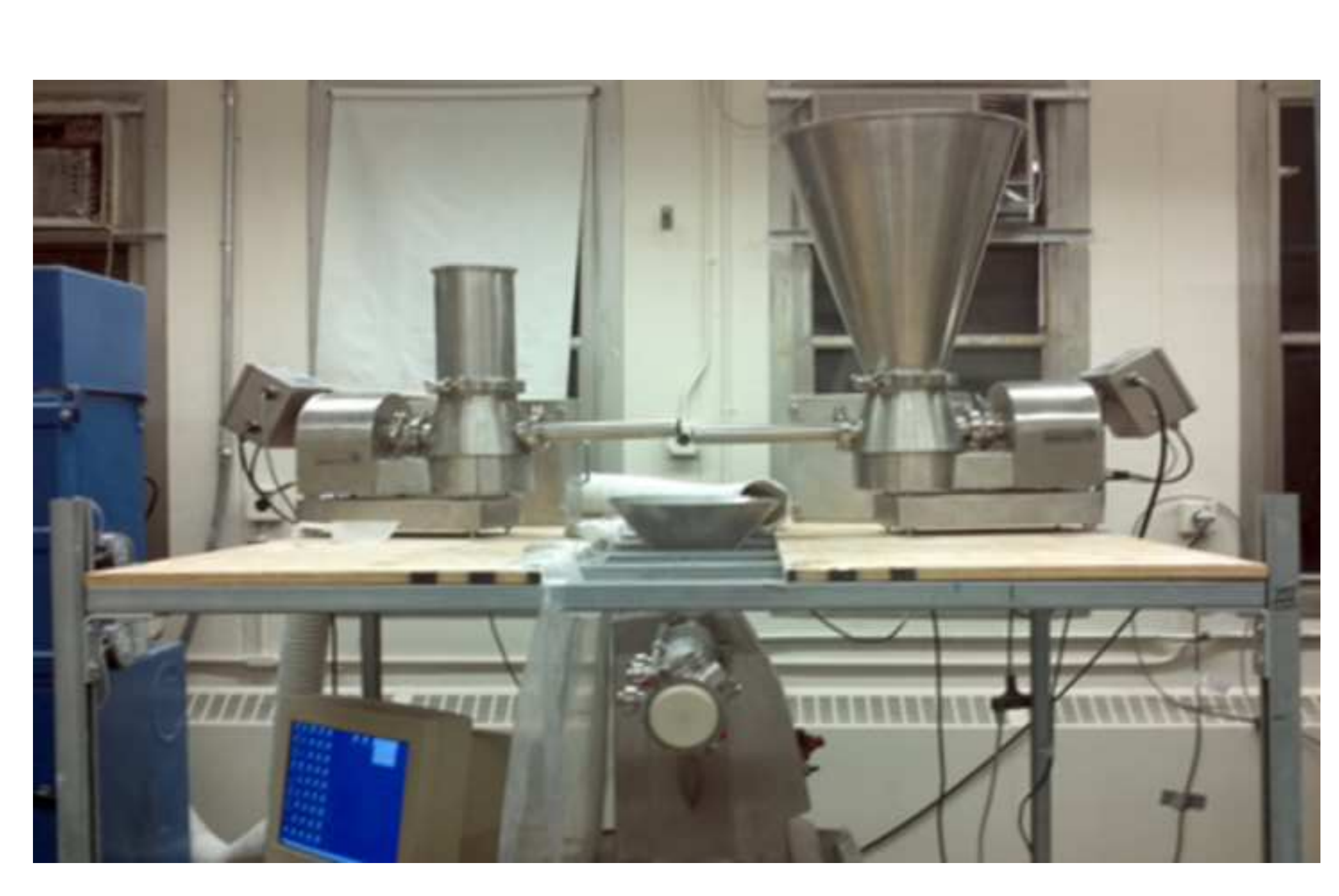

\author{
(18)
}

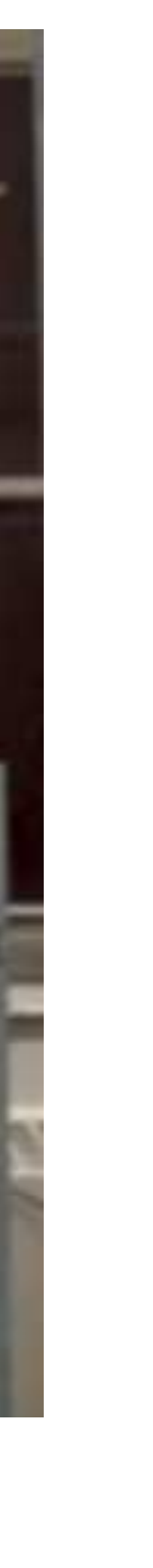


Angled
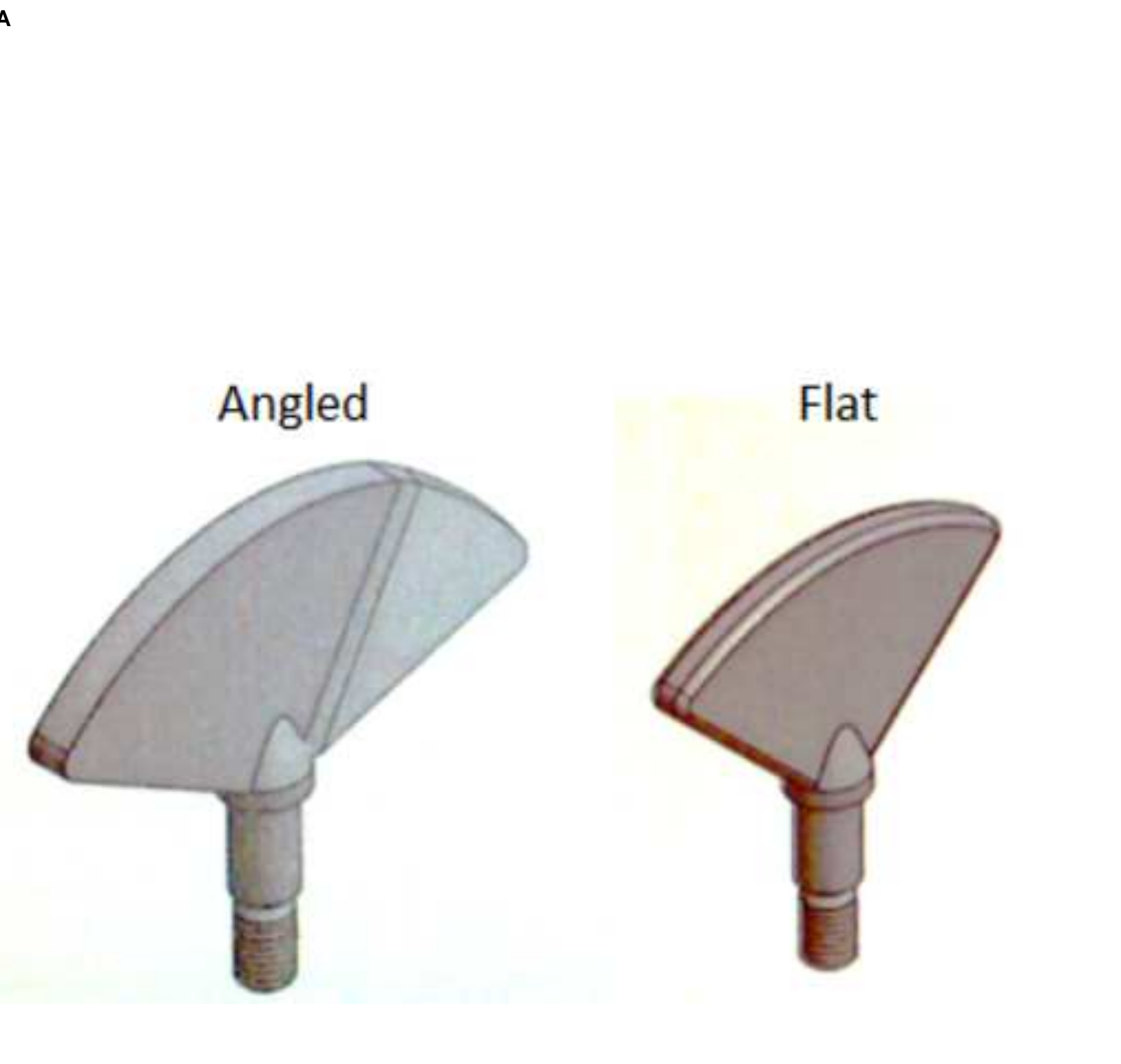

\author{
Figure $2 A$
}

Flat Small

Flat Small
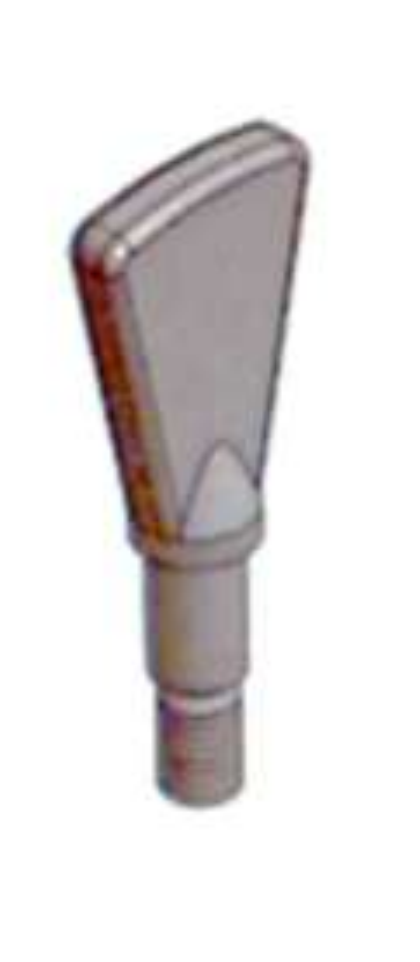

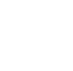

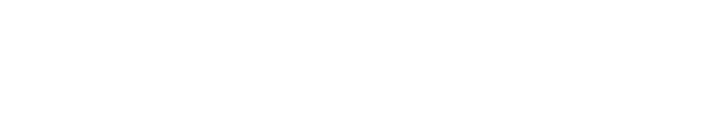




\section{Figure 2B}

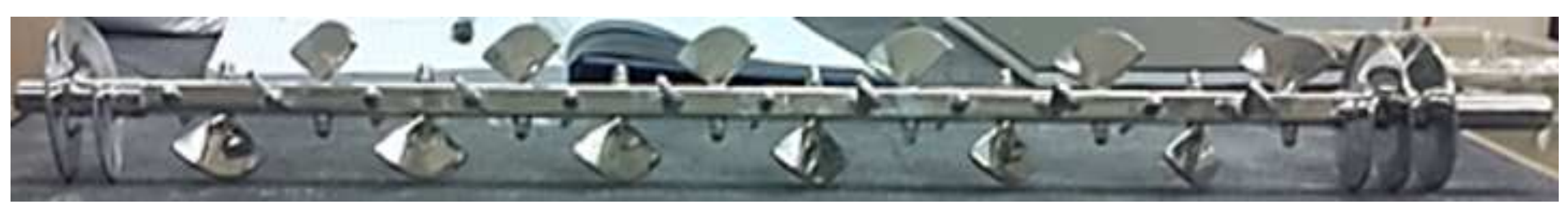


$\leadsto 15 \mathrm{~kg} / \mathrm{hr}=-30 \mathrm{~kg} / \mathrm{hr} \longrightarrow 45 \mathrm{~kg} / \mathrm{hr}$

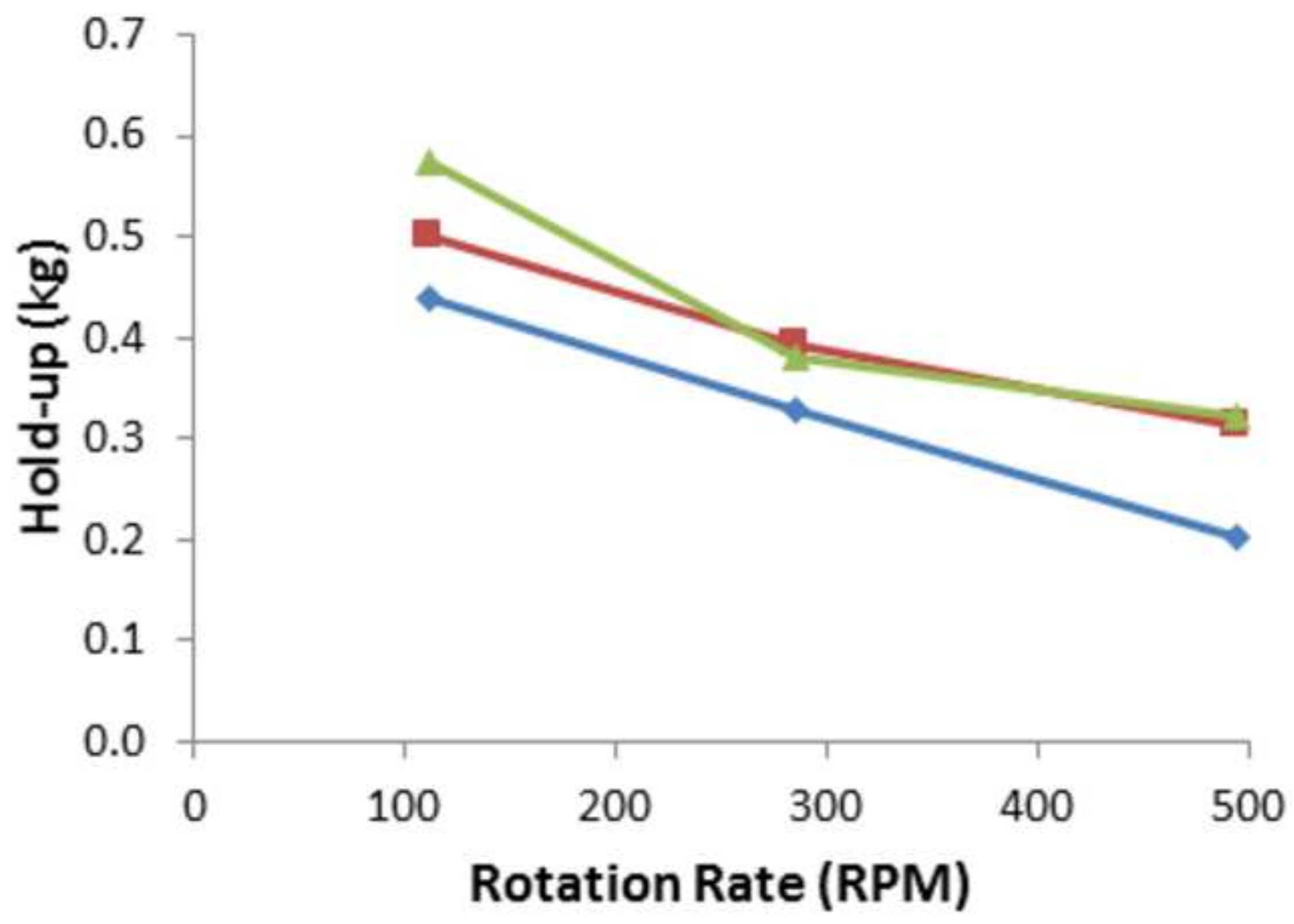


$\leadsto 112 \mathrm{RPM}=286 \mathrm{RPM}=495 \mathrm{RPM}$

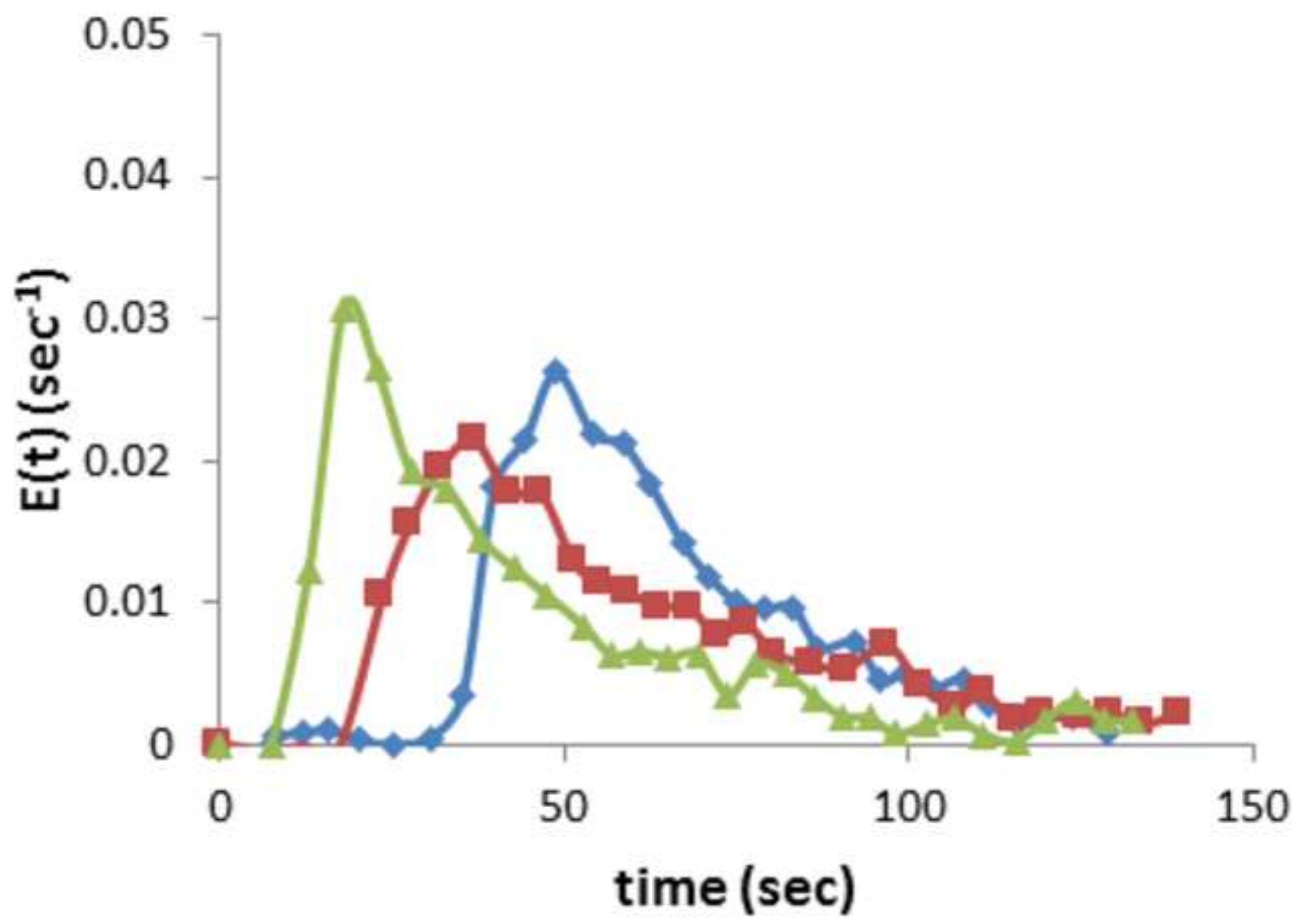


$\leadsto 15 \mathrm{~kg} / \mathrm{hr}=-30 \mathrm{~kg} / \mathrm{hr} \longrightarrow 45 \mathrm{~kg} / \mathrm{hr}$

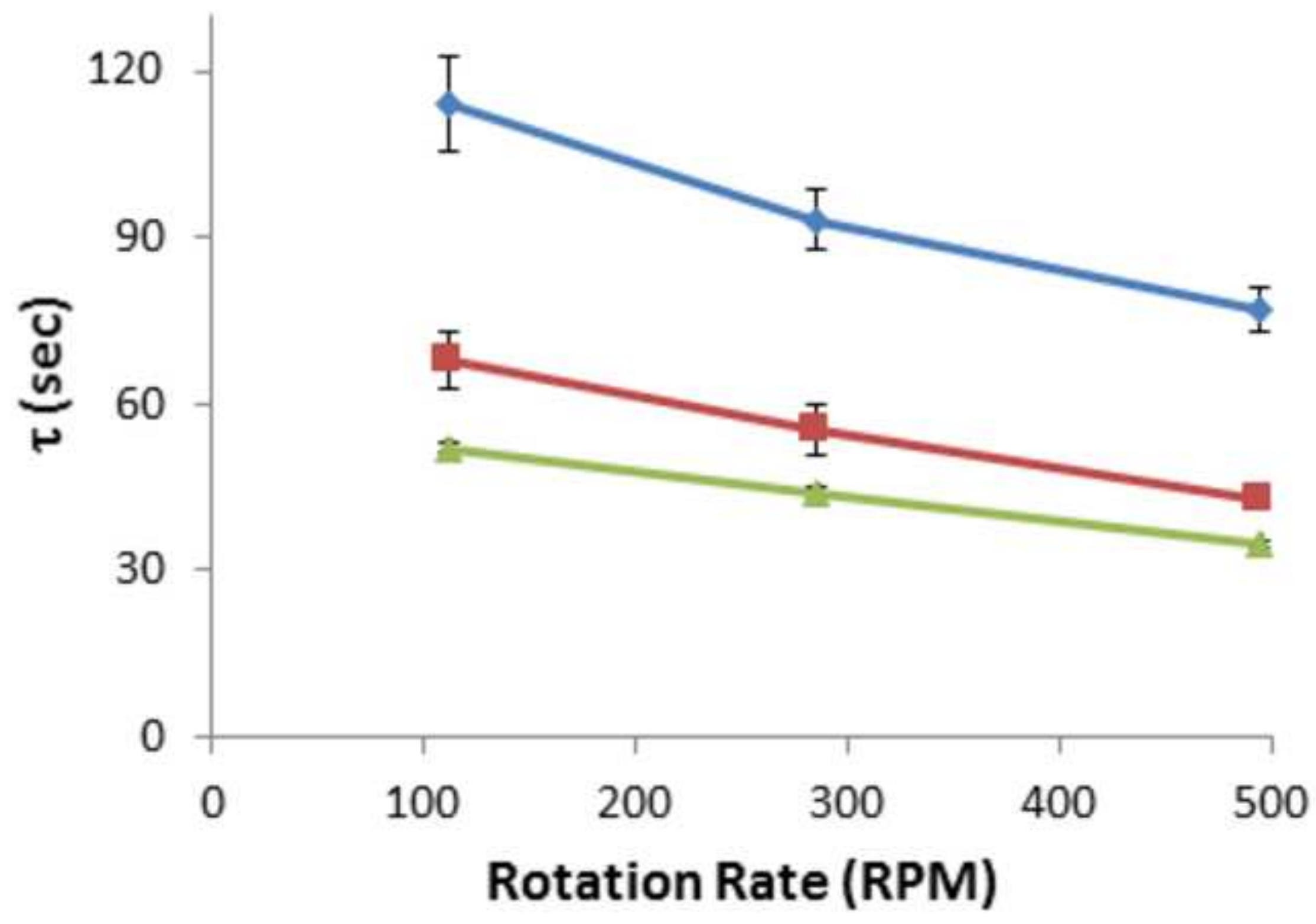


$\longrightarrow 15 \mathrm{~kg} / \mathrm{hr}=-30 \mathrm{~kg} / \mathrm{hr} \rightarrow 45 \mathrm{~kg} / \mathrm{hr}$

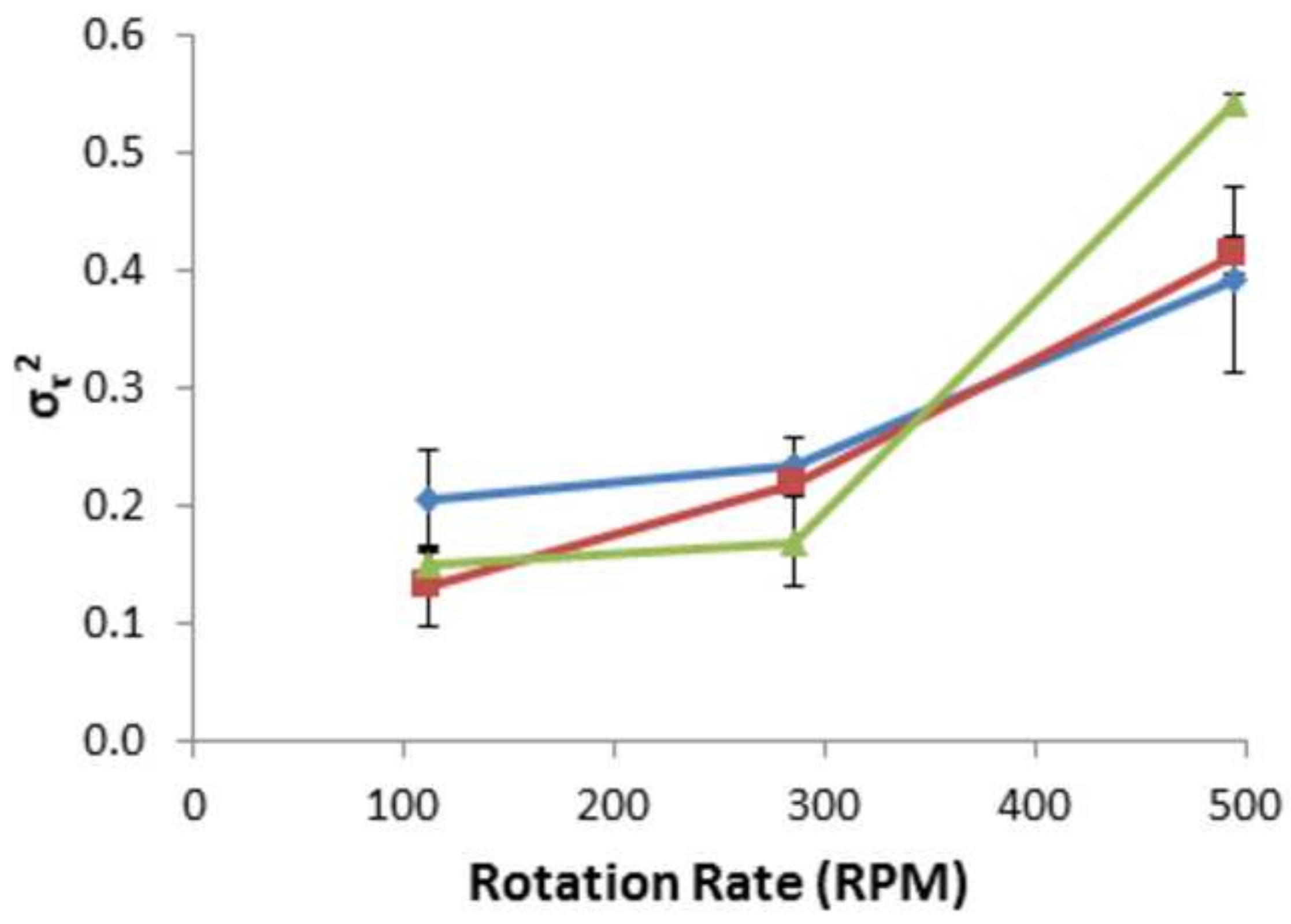


$-15 \mathrm{~kg} / \mathrm{hr}=-30 \mathrm{~kg} / \mathrm{hr}=45 \mathrm{~kg} / \mathrm{hr}$

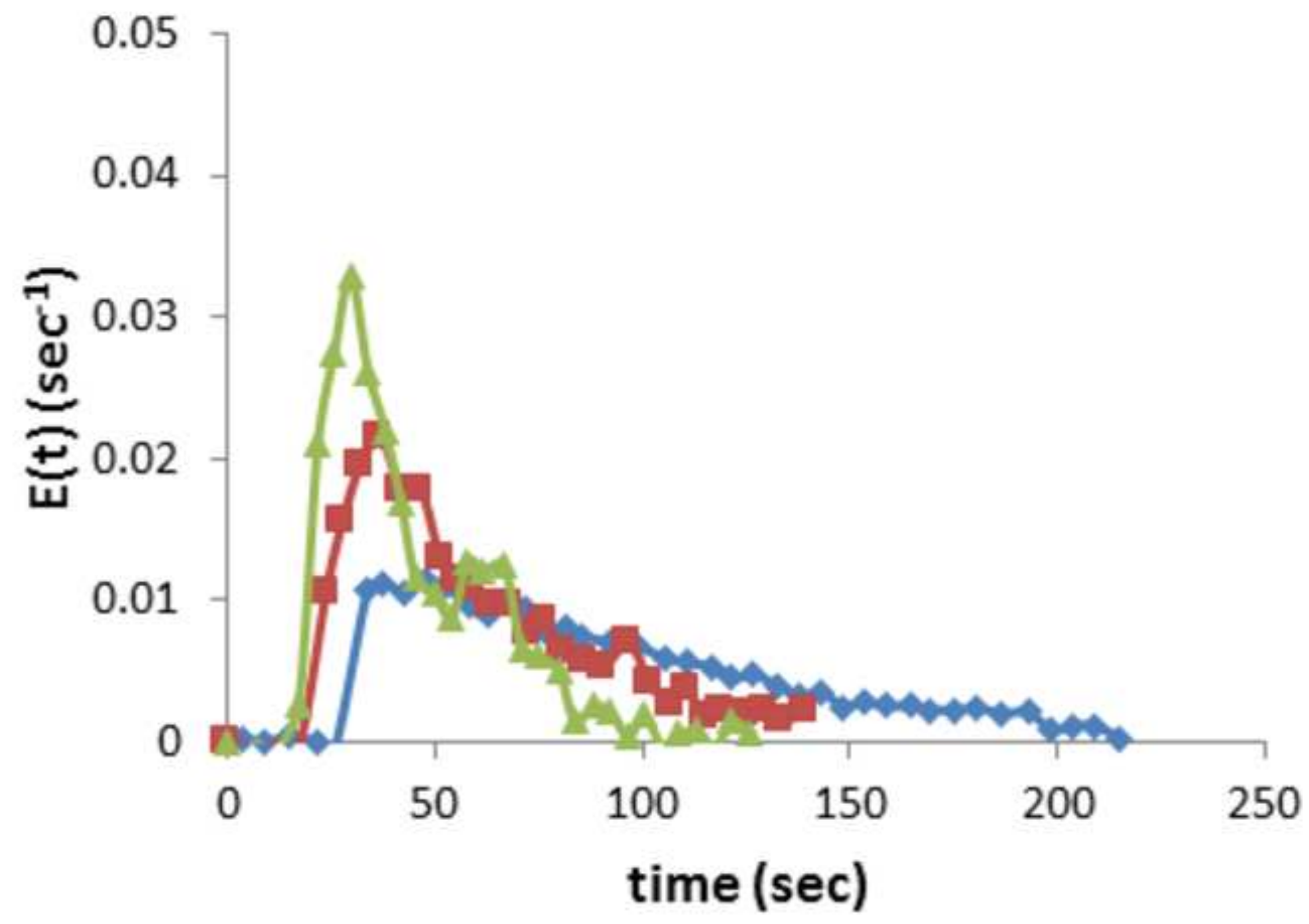


$\longrightarrow 15 \mathrm{~kg} / \mathrm{hr}=-30 \mathrm{~kg} / \mathrm{hr} \longrightarrow 45 \mathrm{~kg} / \mathrm{hr}$

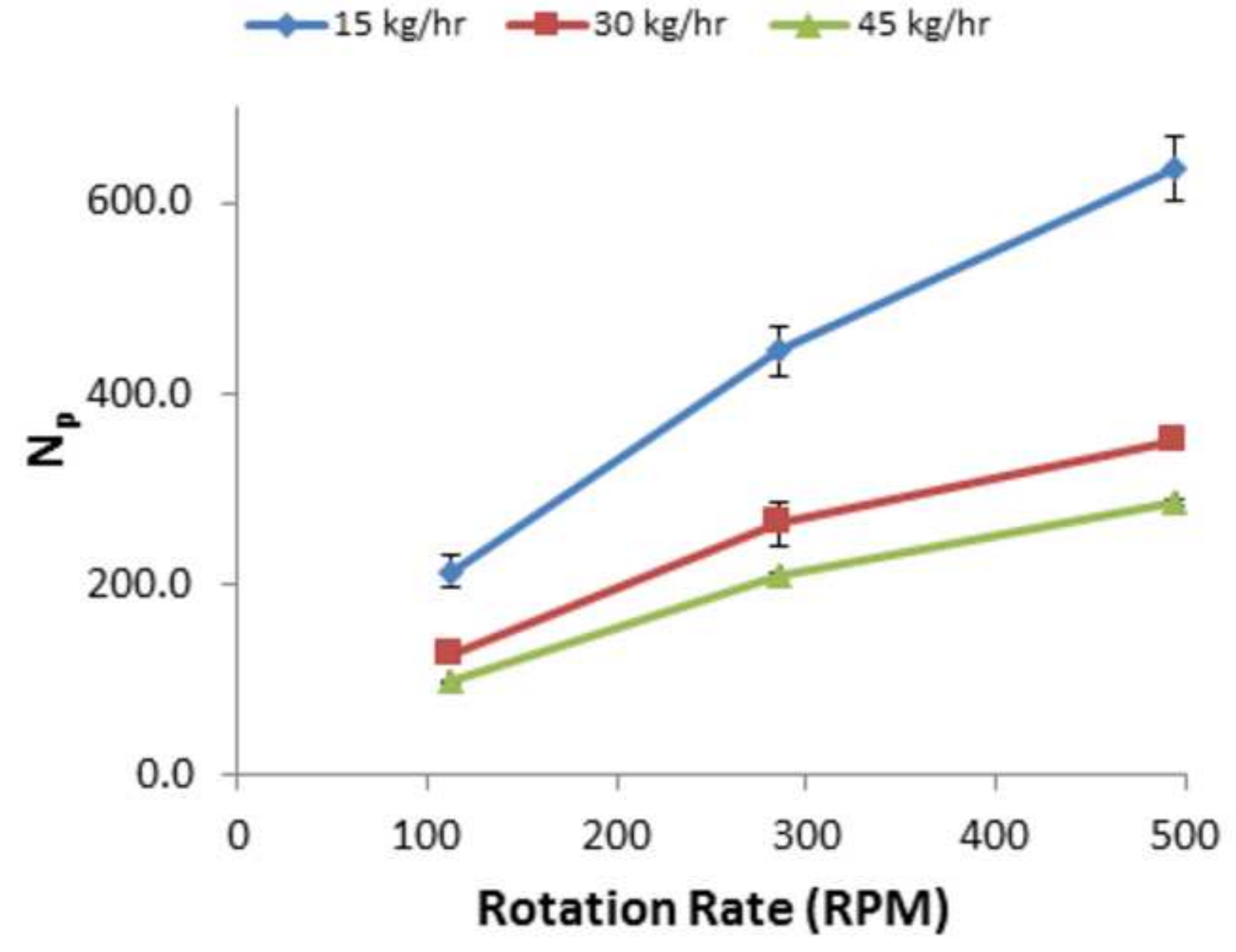


$\leadsto 15 \mathrm{~kg} / \mathrm{hr}=-30 \mathrm{~kg} / \mathrm{hr} \longrightarrow-45 \mathrm{~kg} / \mathrm{hr}$

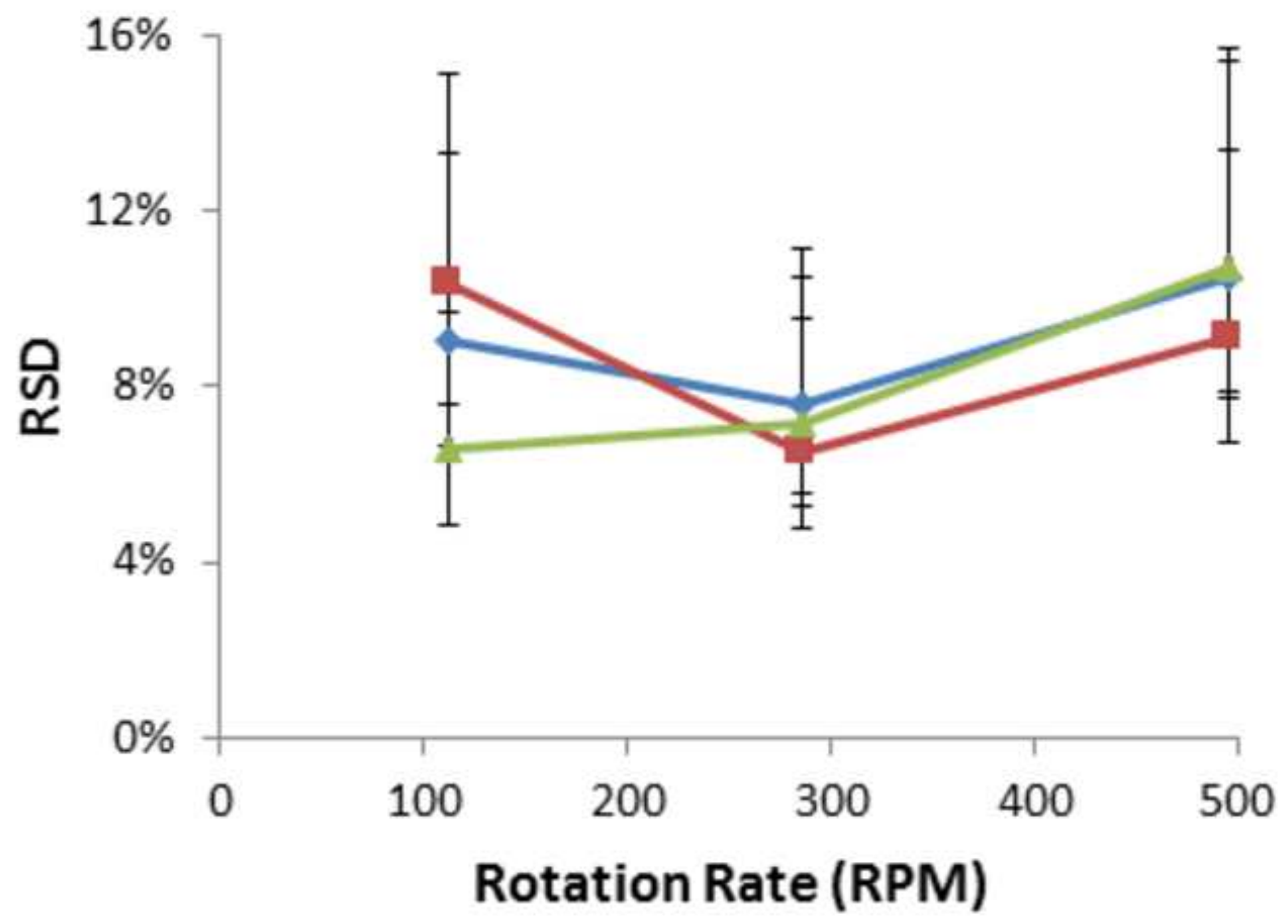


$15 \mathrm{~kg} / \mathrm{hr}$ - 112 RPM

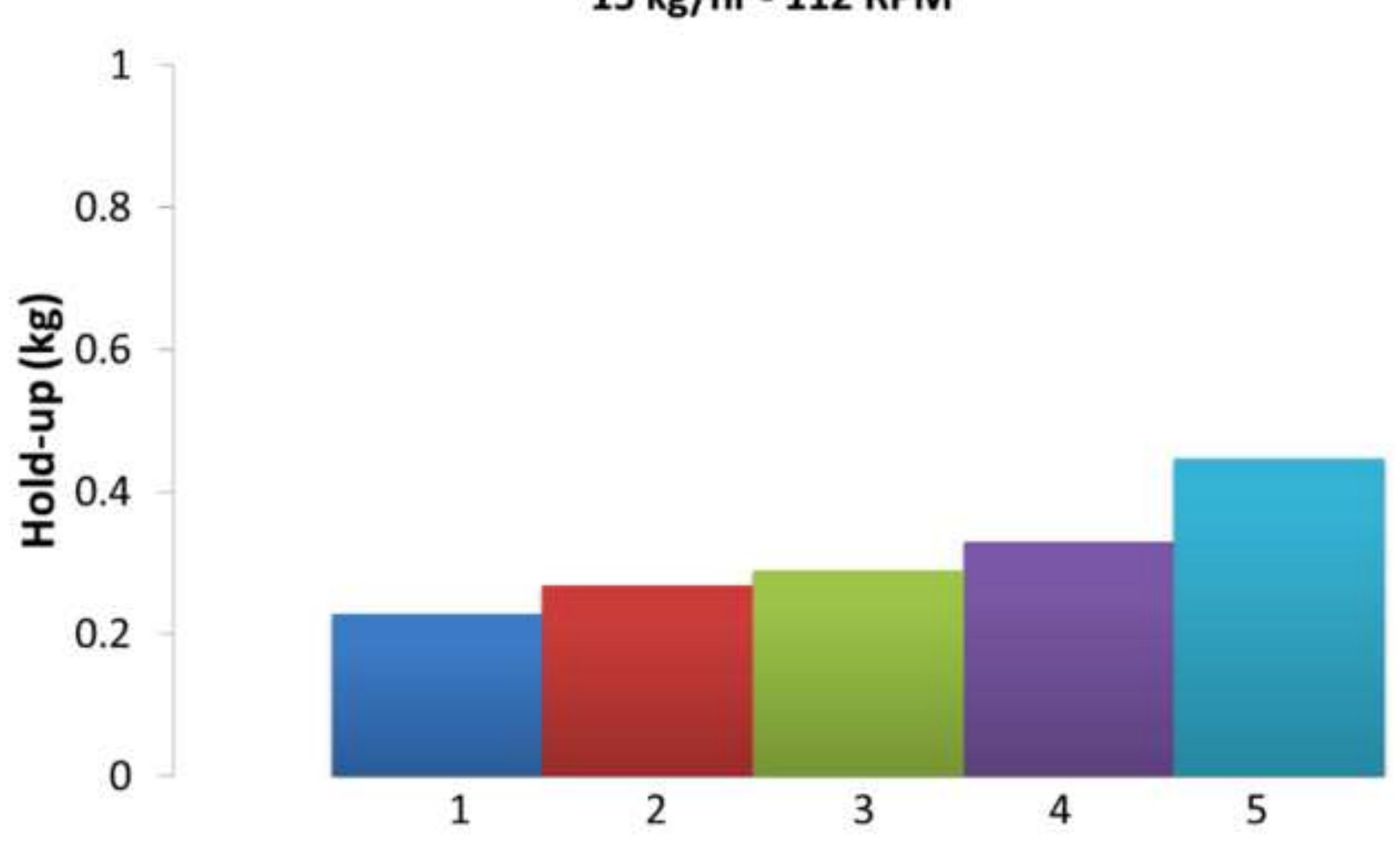

4

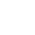


$15 \mathrm{~kg} / \mathrm{hr}$ - $495 \mathrm{RPM}$
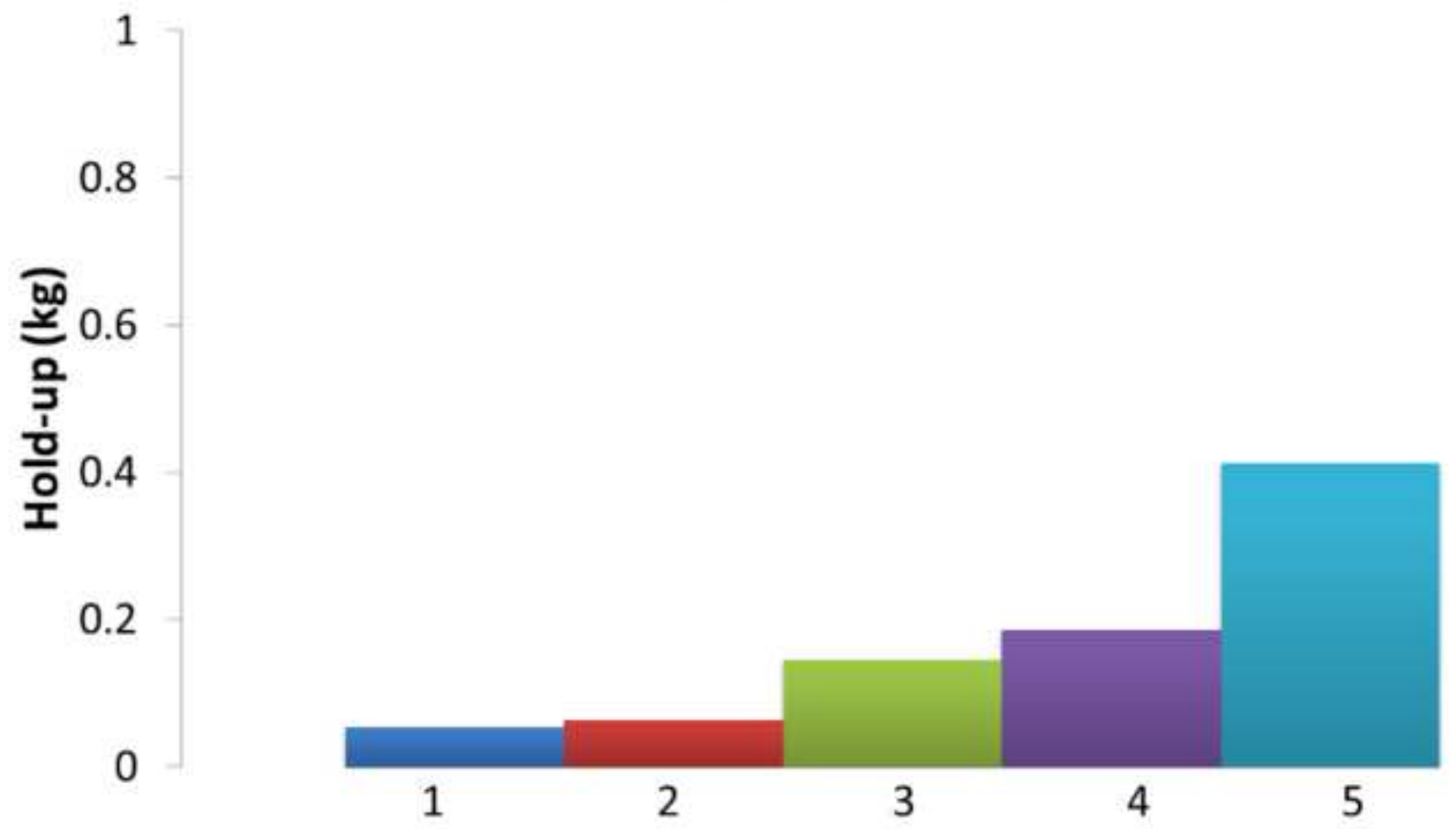
45 kg/hr - 112 RPM
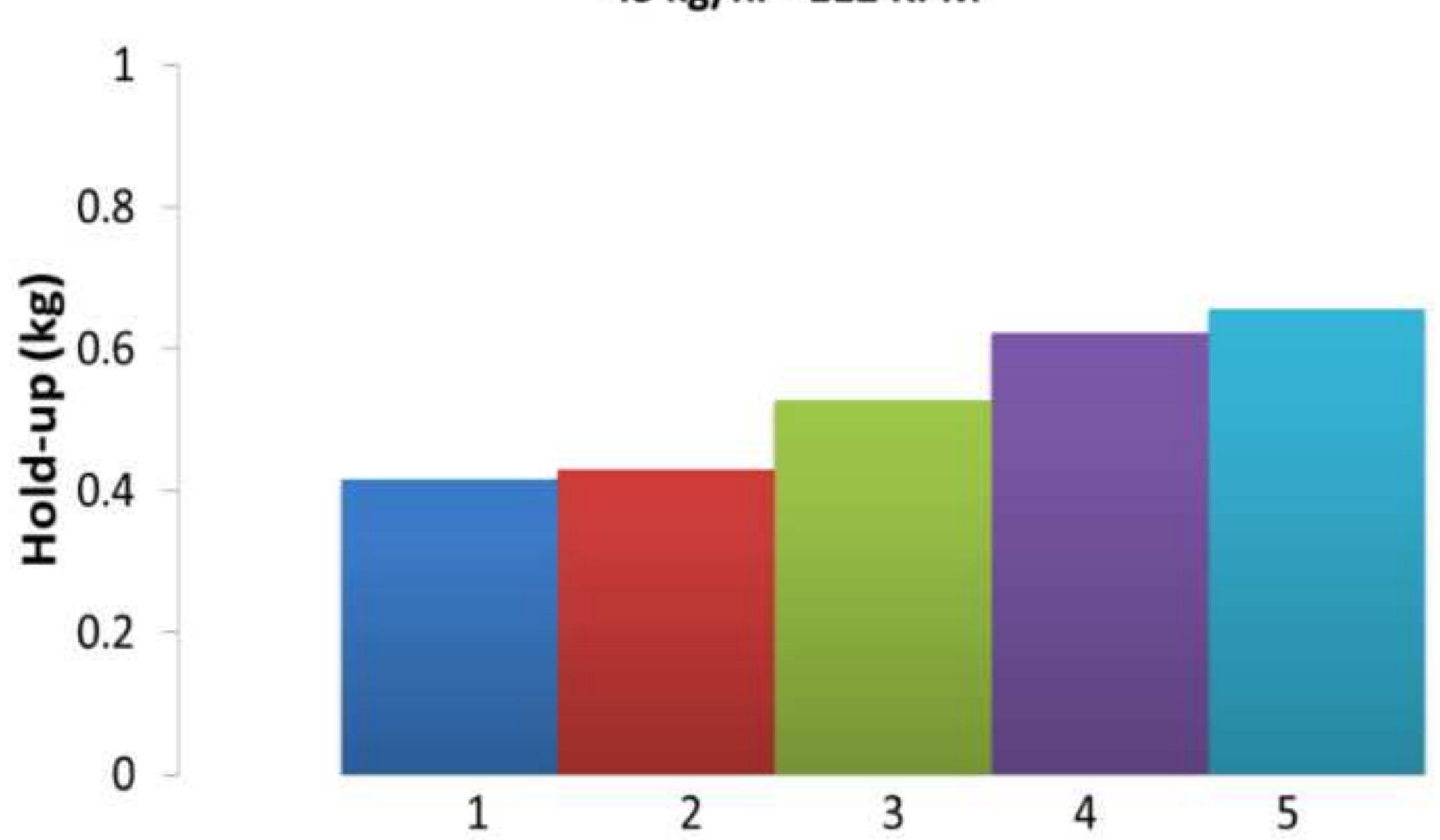
1
2
3
4
5 
$45 \mathrm{~kg} / \mathrm{hr}-495 \mathrm{RPM}$
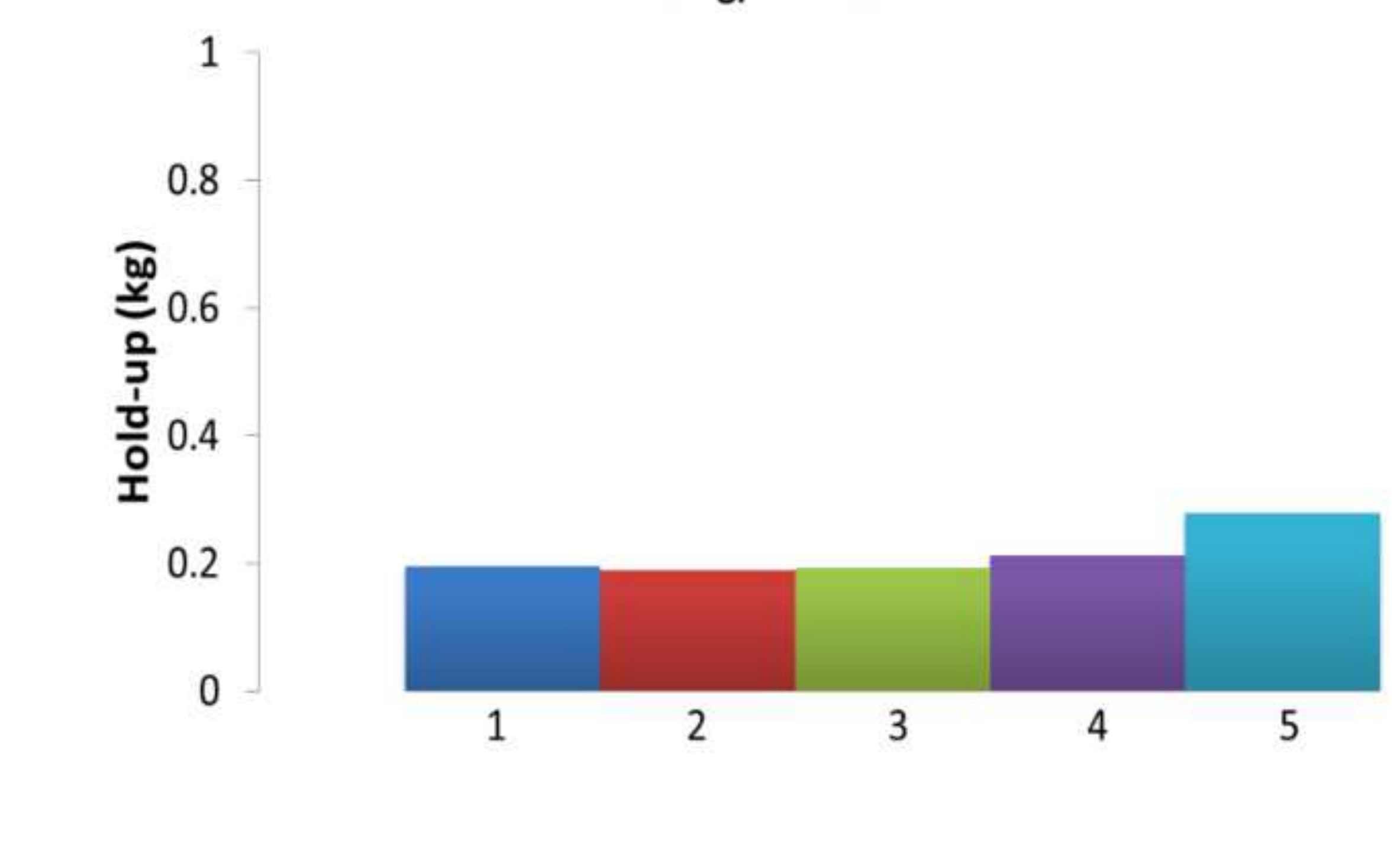

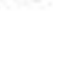

.
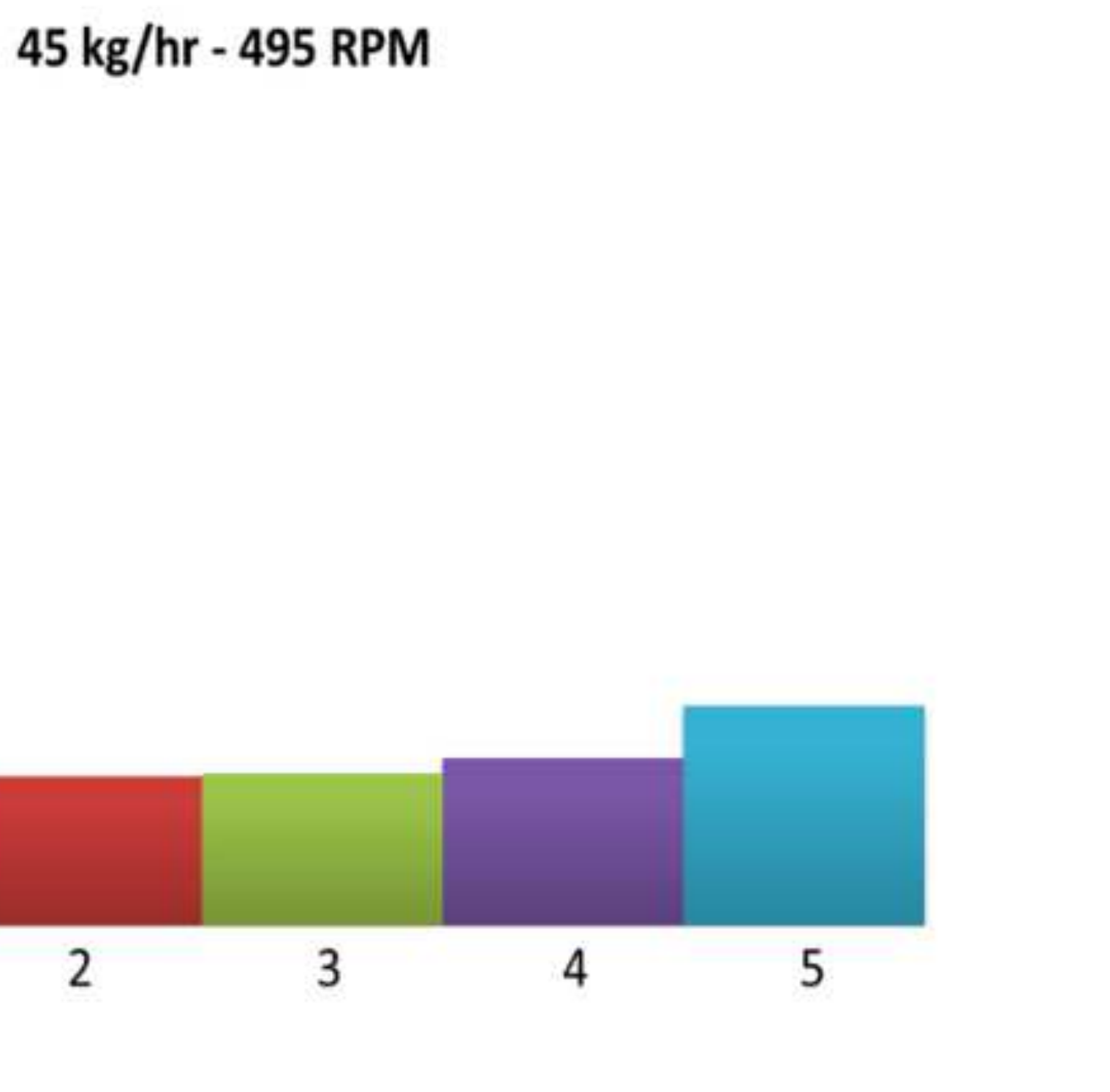

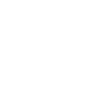


$15 \mathrm{~kg} / \mathrm{hr}$ - 112 RPM

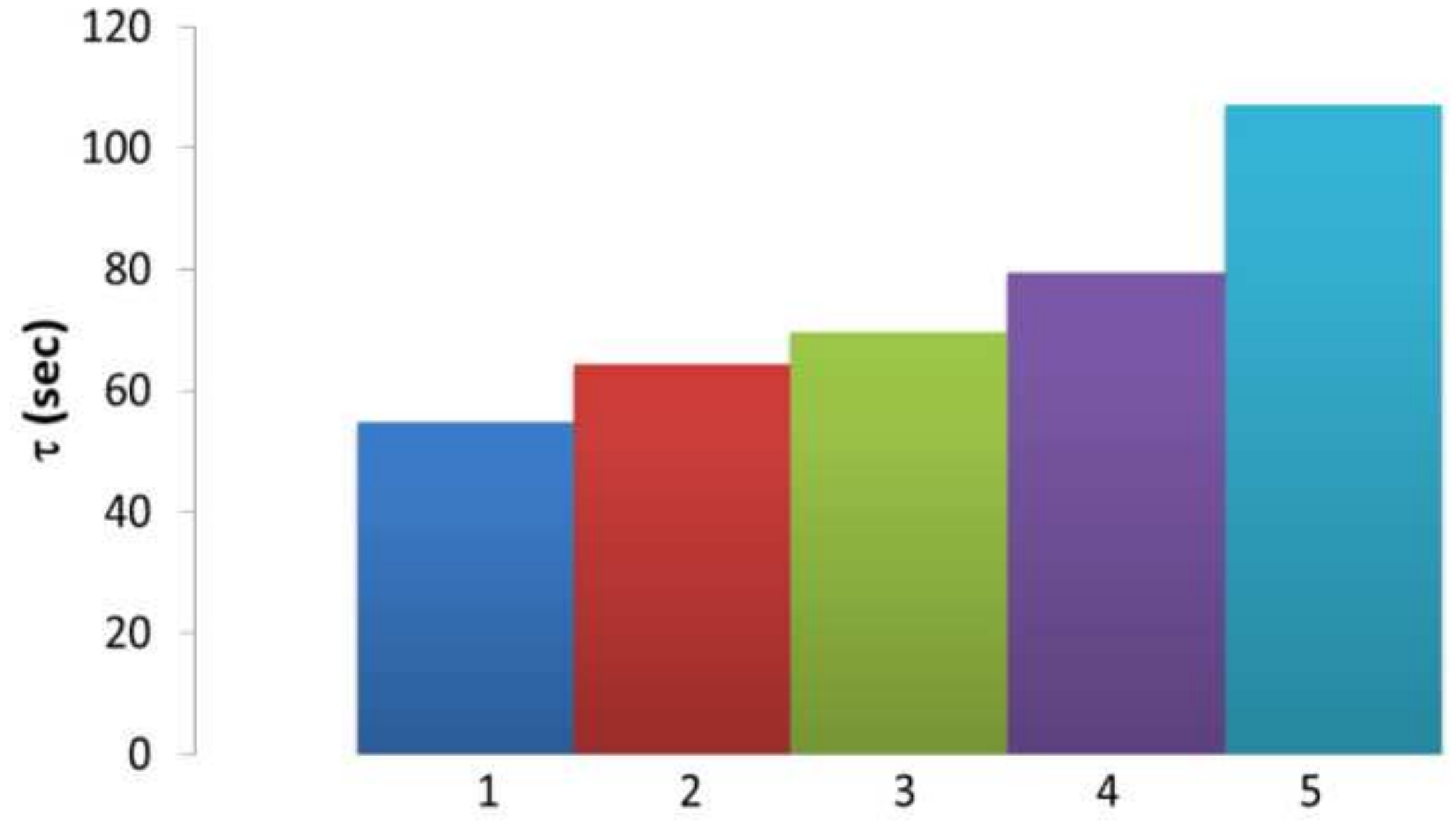


$15 \mathrm{~kg} / \mathrm{hr}$ - 495 RPM

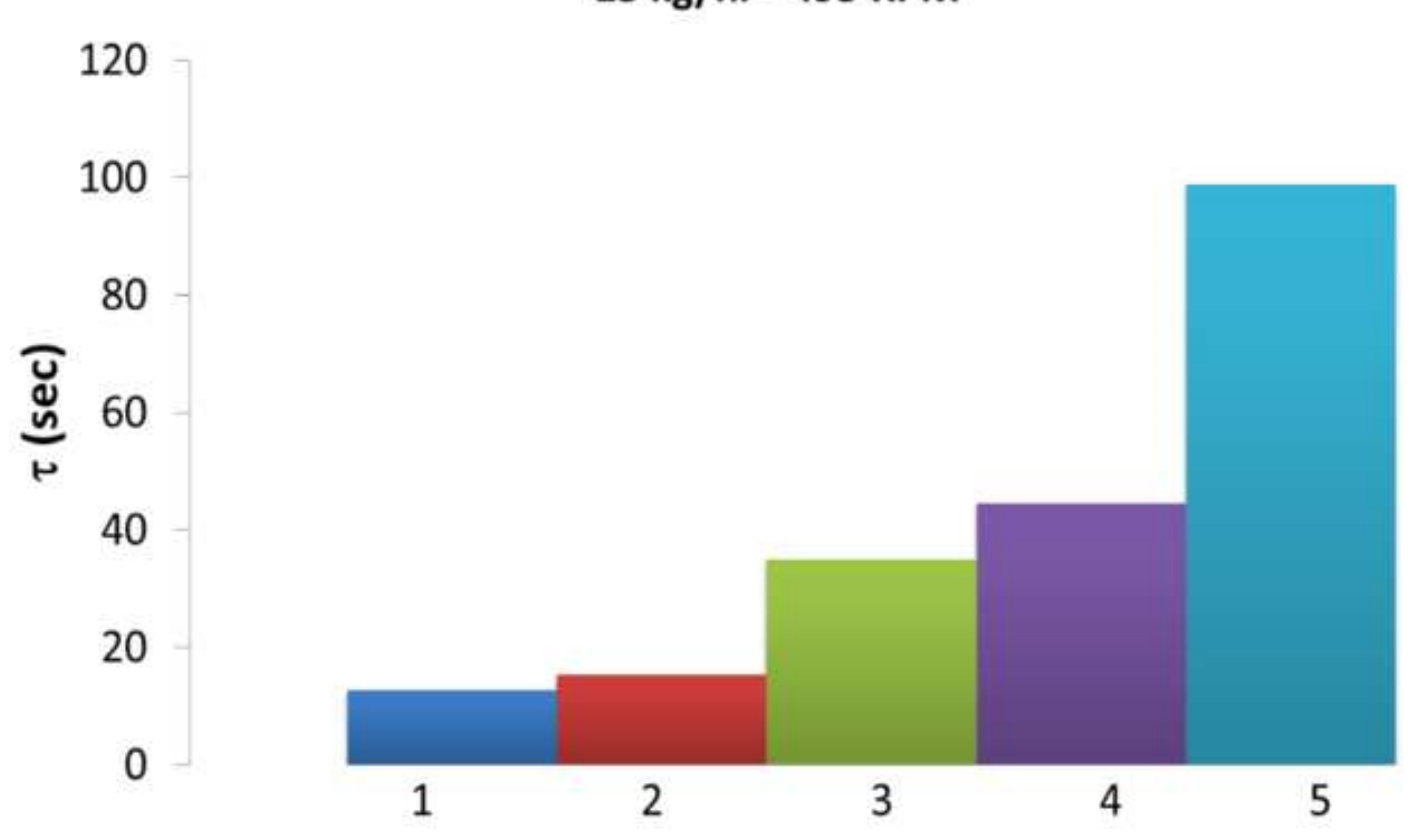

3

4

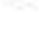




\section{$45 \mathrm{~kg} / \mathrm{hr}$ - 112 RPM}
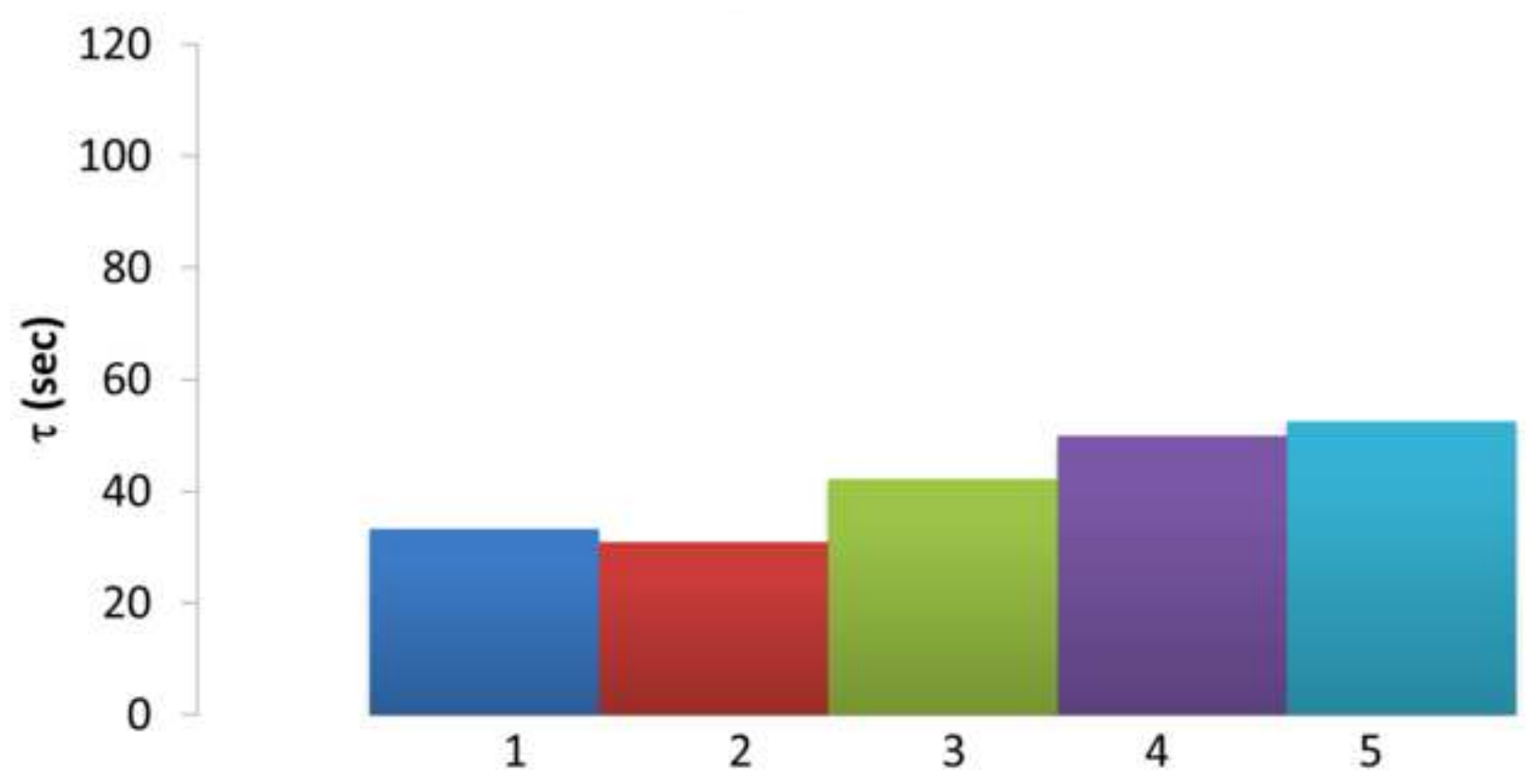

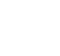




\section{5 kg/hr - 495 RPM}

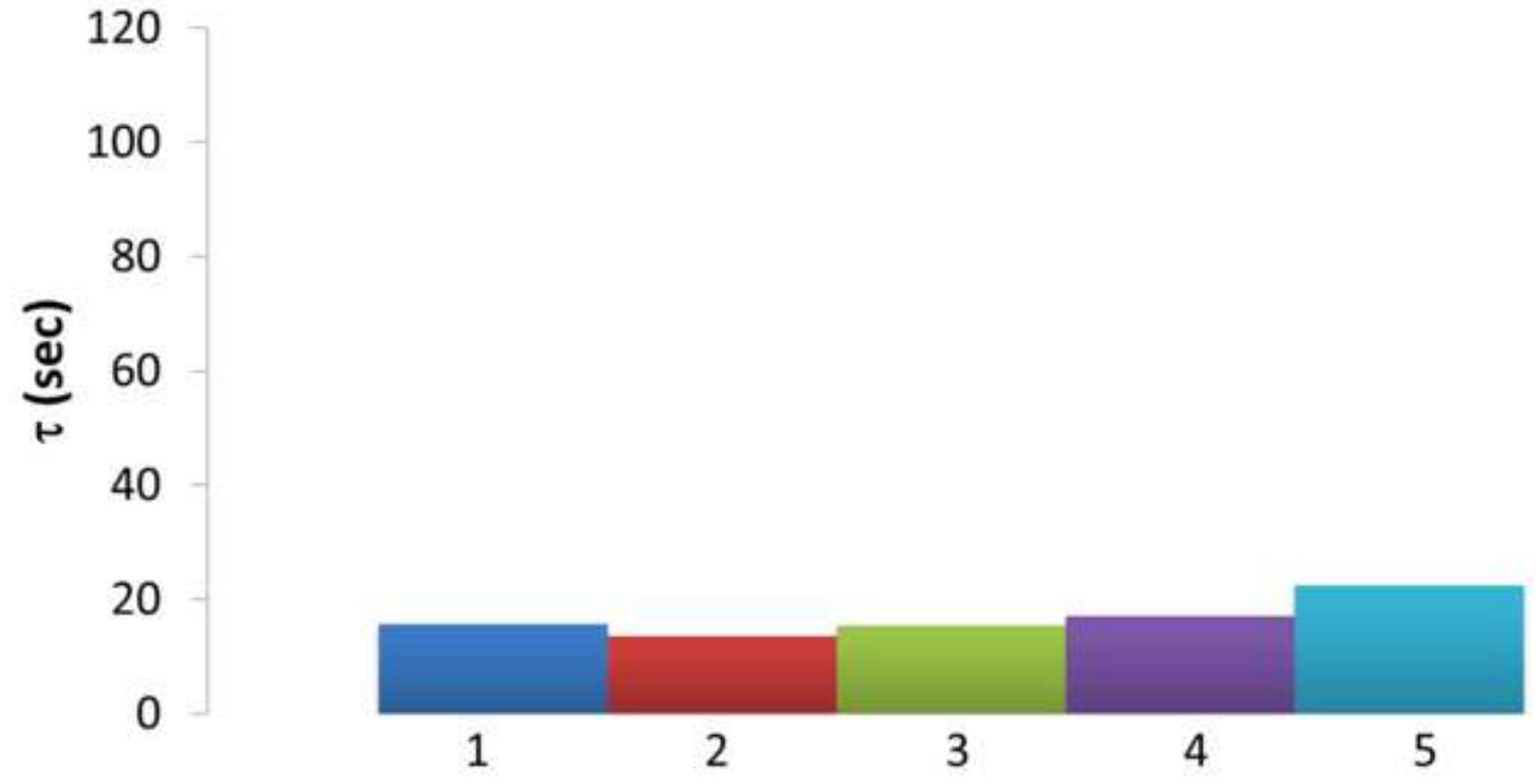




\section{$15 \mathrm{~kg} / \mathrm{hr}$ - 112 RPM}
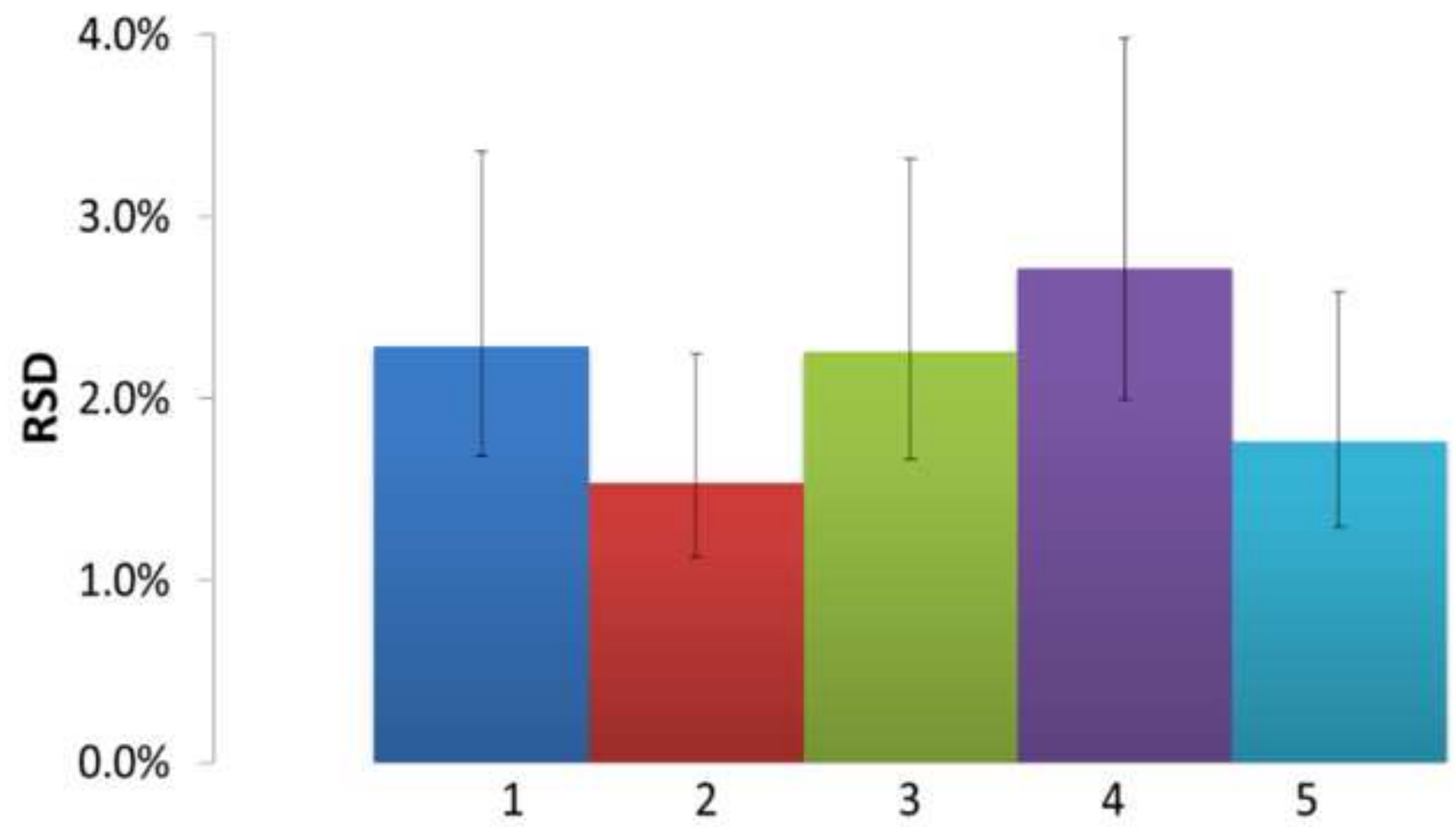


\begin{tabular}{|c|c|c|c|}
\hline Material & Type / Name & Vendor & Mean particle Size $(\mu \mathrm{m})$ \\
\hline Silicified Microcrystalline Cellulose & Prosolv HD 90 & JRS Pharma & 110 \\
\hline Microcrystalline Cellulose & Avicel PH 200 & FMC Biopolymers & 220 \\
\hline Magnesium Stearate & Magnesium Stearate & Mallinckrodt & 10 \\
\hline Acetaminophen & Semi-fine & Mallinckrodt & 45 \\
\hline
\end{tabular}

Table 1 - Description of materials used.

\begin{tabular}{|c|c|c|c|}
\hline Material Fed & Flow Rate $(\mathrm{kg} / \mathrm{hr})$ & Nozzle Size $(\mathrm{mm})$ & Screw Type \\
\hline Acetaminophen & $0.75-5.00$ & 22 & Helix \\
\hline Acetaminophen & $4.50-13.50$ & 36 & Auger \\
\hline Avicel PH200 & $10.50-31.50$ & 36 & Auger \\
\hline Prosolv HD90 & $14.25-42.75$ & 36 & Auger \\
\hline
\end{tabular}

Table 2 - Feeder configurations for each material depending on their concentration (individual flow rate).

\begin{tabular}{|c|c|c|c|c|c|c|c|c|}
\hline $\begin{array}{c}\text { Material } \\
\text { of Interest }\end{array}$ & Excipient & $\begin{array}{c}\text { Target } \\
\text { Concentration } \\
(\%)\end{array}$ & $\mathrm{R}^{2}$ & RMSEC & RMSEP & $\begin{array}{c}\text { Concentration } \\
\text { Range (\%) }\end{array}$ & Filter & Points \\
\hline MgSt & Avicel PH 200 & $0-7$ & 0.9939 & 0.218 & 0.215 & $0-7$ & SG & 9,3 \\
\hline APAP & Avicel PH 200 & 30 & 0.9672 & 0.293 & 0.361 & $27-33$ & SG & 7,3 \\
\hline MgSt & Prosolv HD90 & $0-8$ & 0.9964 & 0.207 & 0.203 & $0-8$ & SG & 7,3 \\
\hline APAP & Prosolv HD90 & 5 & 0.9808 & 0.238 & 0.297 & $0-7$ & SG & 11,5 \\
\hline
\end{tabular}

Table 3 - NIR calibration model description. Root mean squared error of calibration (RMSEC) and prediction (RMSEP) are used as measures of the accuracy of each calibration model. A second-order polynomial Savitzky-Golay (SG) filtering was used as indicated. 
(A)

\begin{tabular}{|c|c|c|c|}
\hline Blade Type & Diameter & Length $(\mathbf{c m})$ & $\begin{array}{c}\text { Angled Tip } \\
\text { Length }(\mathbf{c m})\end{array}$ \\
\hline Angled & 2.6 & 4 & 1.5 \\
\hline Flat & 2.6 & 4 & - \\
\hline Small & 2.6 & 1.7 & - \\
\hline
\end{tabular}

(B)

\begin{tabular}{|c|c|c|}
\hline Blade Configuration \# & Blades & Blade configuration \\
\hline 1 & Angled & all forward \\
\hline 2 & Angled + Flat & all forward \\
\hline 3 & Angled + Flat & $1 / 3$ All-forward $+1 / 3$ alternate $+1 / 3$ all forward \\
\hline 4 & Angled + Small & all forward \\
\hline 5 & Angled + Small & $1 / 2$ all forward $+1 / 2$ alternate \\
\hline
\end{tabular}

Table $4-$ (A) Blade specifications and (B) blade configurations.

\begin{tabular}{|c|c|c|c|c|c|}
\hline & \multicolumn{5}{|c|}{ F-values } \\
\hline & Hold-up & MRT & MCV & $N_{p}$ & $\mathrm{RSD}^{2}$ \\
\hline Rotation Rate & 50.11 & 55.49 & 107.17 & 390.85 & 1.44 \\
\hline Flow Rate & 11.15 & 226.71 & 1.16 & 302.85 & 3.05 \\
\hline \multirow[t]{2}{*}{ Rotation Rate*Flow Rate } & N/A & 2.65 & 6.19 & 26.37 & N/A \\
\hline & \multicolumn{5}{|c|}{$p$-values } \\
\hline Rotation Rate & 0.001 & 0.000 & 0.000 & 0.000 & 0.273 \\
\hline Flow Rate & 0.023 & 0.000 & 0.357 & 0.000 & 0.082 \\
\hline \multirow[t]{3}{*}{ Rotation Rate*Flow Rate } & $\mathrm{N} / \mathrm{A}$ & 0.104 & 0.011 & 0.000 & N/A \\
\hline & \multicolumn{5}{|c|}{$\begin{array}{c}R^{2}, \\
R_{a d j}^{2}\end{array}$} \\
\hline & $\begin{array}{l}96.84 \% \\
93.68 \%\end{array}$ & $\begin{array}{l}98.46 \% \\
97.09 \%\end{array}$ & $\begin{array}{l}96.41 \% \\
93.21 \%\end{array}$ & $\begin{array}{l}99.40 \% \\
98.87 \%\end{array}$ & $\begin{array}{l}40.85 \%, \\
22.66 \%\end{array}$ \\
\hline
\end{tabular}

Table 5 - Summary of analysis of variance (ANOVA) for hold-up, MRT, MCV, $N_{p}$, and normalized variance $\left(\mathrm{RSD}^{2}\right)$ for mixing characterization study. $F$-values: Fisher statistic values, and $p$-values: statistical significance. Confidence levels for all intervals: $95 \%$. 


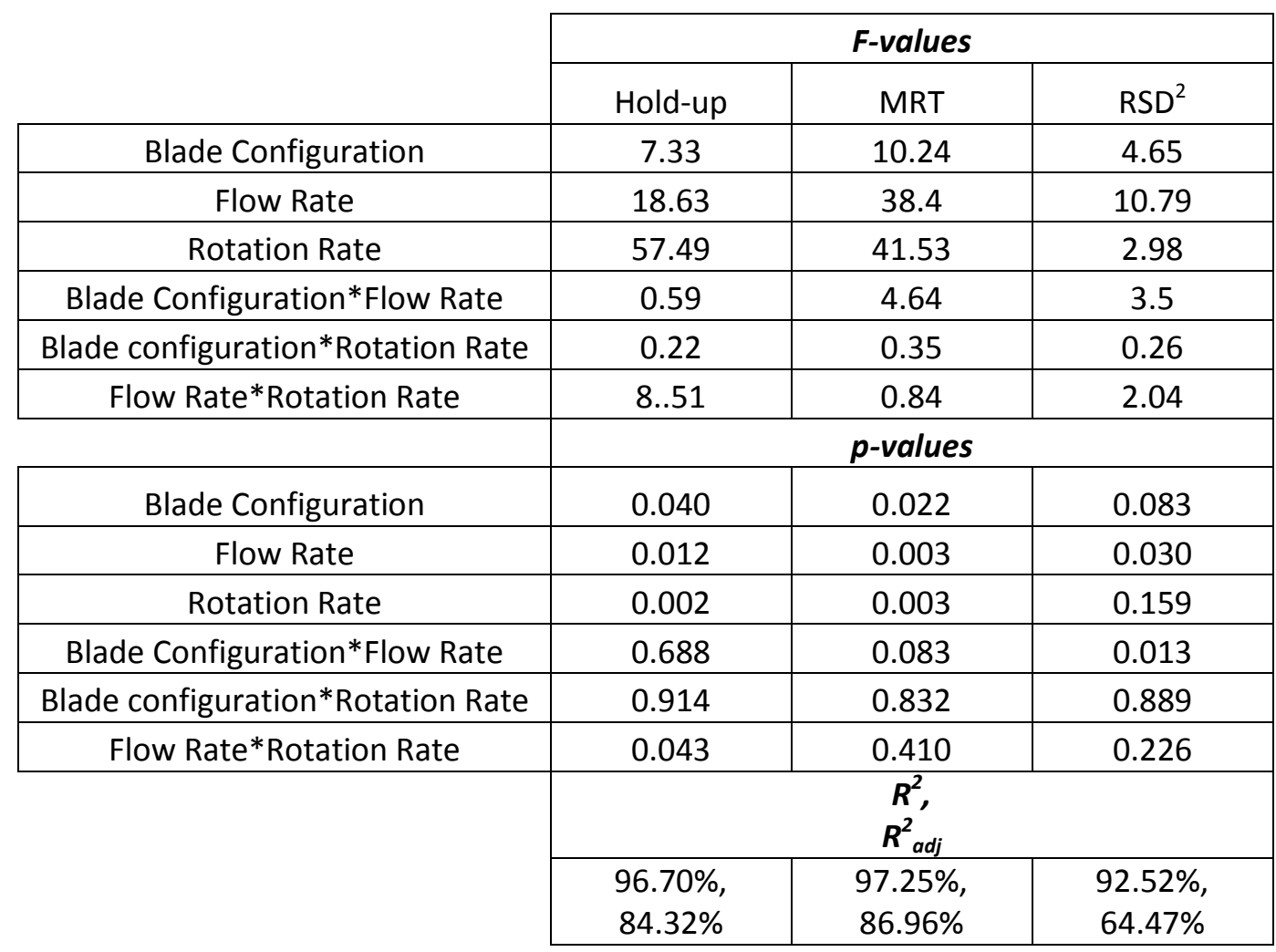

Table 6 - Summary of analysis of variance (ANOVA) for hold-up, MRT, and normalized variance $\left(\mathrm{RSD}^{2}\right)$ for blade configuration study. F-values: Fisher statistic values, and p-values: statistical significance. Confidence levels for all intervals: $95 \%$. 

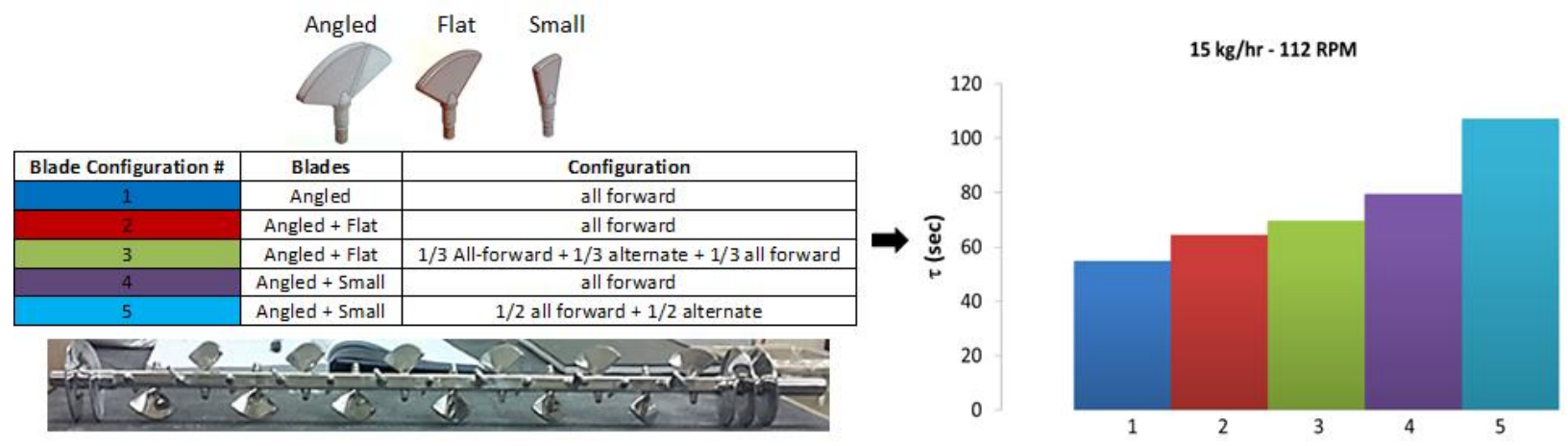